NATIONAL LABORATORY

\title{
Analyses to Verify and Improve the Accuracy of the Manufactured Home Energy Audit (MHEA)
}

December 2008

\section{Prepared by}

Mark P. Ternes

Michael B. Gettings

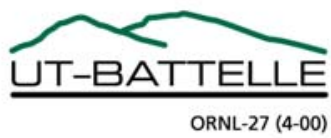




\title{
DOCUMENT AVAILABILITY
}

Reports produced after January 1, 1996, are generally available free via the U.S. Department of Energy (DOE) Information Bridge.

Web site http://www.osti.gov/bridge

Reports produced before January 1, 1996, may be purchased by members of the public from the following source.

\author{
National Technical Information Service \\ 5285 Port Royal Road \\ Springfield, VA 22161 \\ Telephone 703-605-6000 (1-800-553-6847) \\ TDD 703-487-4639 \\ Fax 703-605-6900 \\ E-mail info@ntis.gov \\ Web site http://www.ntis.gov/support/ordernowabout.htm
}

Reports are available to DOE employees, DOE contractors, Energy Technology Data Exchange (ETDE) representatives, and International Nuclear Information System (INIS) representatives from the following source.

Office of Scientific and Technical Information

P.O. Box 62

Oak Ridge, TN 37831

Telephone 865-576-8401

Fax 865-576-5728

E-mail reports@osti.gov

Web site http://www.osti.gov/contact.html

This report was prepared as an account of work sponsored by an agency of the United States Government. Neither the United States Government nor any agency thereof, nor any of their employees, makes any warranty, express or implied, or assumes any legal liability or responsibility for the accuracy, completeness, or usefulness of any information, apparatus, product, or process disclosed, or represents that its use would not infringe privately owned rights. Reference herein to any specific commercial product, process, or service by trade name, trademark, manufacturer, or otherwise, does not necessarily constitute or imply its endorsement, recommendation, or favoring by the United States Government or any agency thereof. The views and opinions of authors expressed herein do not necessarily state or reflect those of the United States Government or any agency thereof. 


\title{
ANALYSES TO VERIFY AND IMPROVE THE ACCURACY OF THE MANUFACTURED HOME ENERGY AUDIT (MHEA)
}

\author{
Mark P. Ternes \\ Michael B. Gettings
}

Date Published: December 2008

Prepared by

OAK RIDGE NATIONAL LABORATORY

Oak Ridge, Tennessee 37831-6283

managed by

UT-BATTELLE, LLC

for the

U.S. DEPARTMENT OF ENERGY

under contract DE-AC05-00OR22725 


\section{CONTENTS}

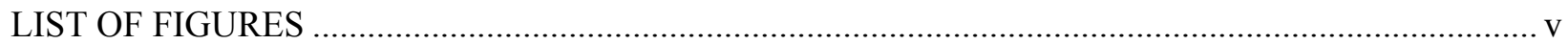

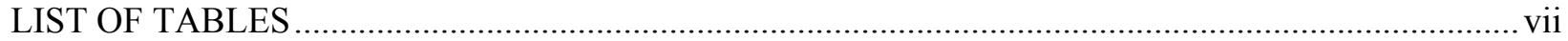

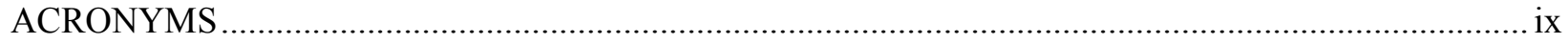

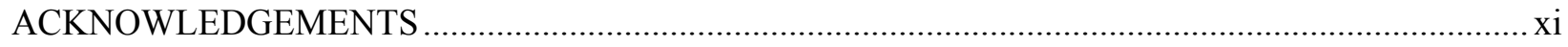

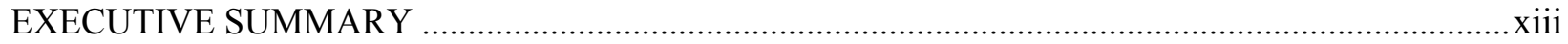

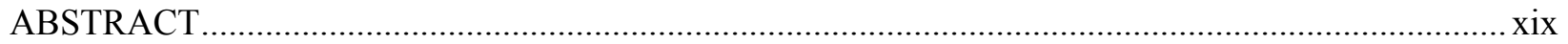

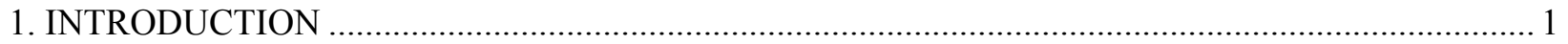

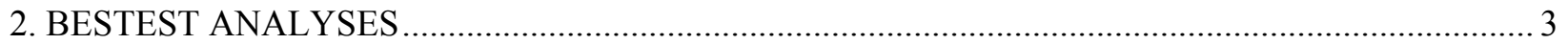

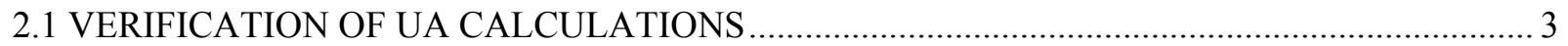

2.2 VERIFICATION OF SPACE-HEATING LOAD CALCULATIONS …................................... 5

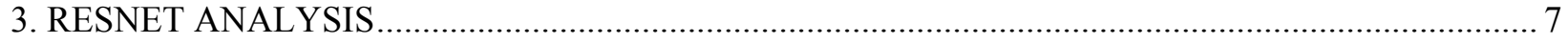

4. ANALYSES TO TRUE-UP ENERGY ESTIMATES TO MEASURED VALUES ............................. 9

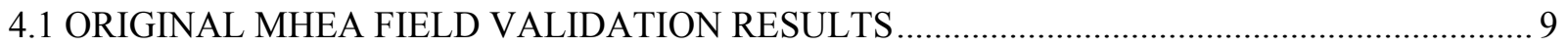

4.2 RESULTS FOLLOWING UA-CALCULATION MODIFICATIONS ....................................... 9

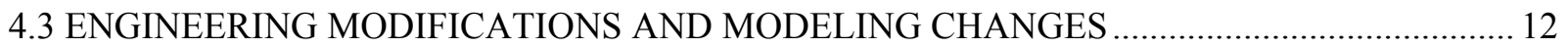

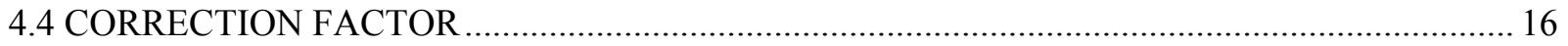

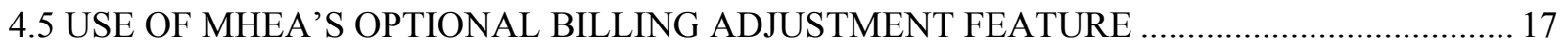

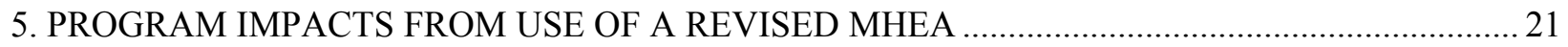

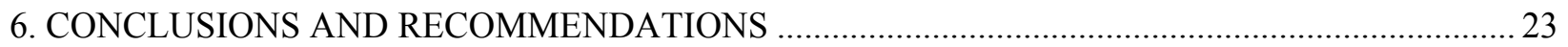

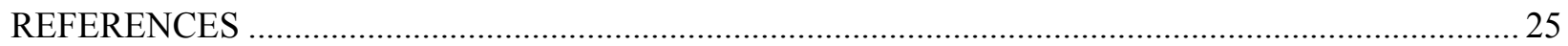

APPENDIX A. CHANGES MADE IN MHEA DURING THE BESTEST ANALYSES ...................... 27

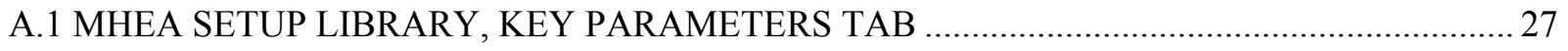

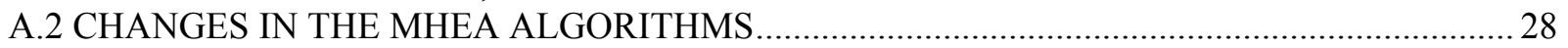




\section{LIST OF FIGURES}

ES.1 Comparison of MHEA's estimated annual energy savings to the actual measured energy savings in each of the 43 mobile homes with high-quality data as determined (a) in the original MHEA field validation study, (b) after modifications and a 0.6 correction factor were incorporated into MHEA, and (c) after MHEA's billing adjustment feature was used together with the modifications and 0.6 correction factor ..... xvi

4.1 Comparison of MHEA's estimate of the pre-weatherization annual energy consumption to the actual measured energy consumption in each of the 43 mobile homes with highquality data as determined in the original MHEA field validation study

4.2 Comparison of MHEA's estimate of the post-weatherization annual energy consumption to the actual measured energy consumption in each of the 43 mobile homes with highquality data as determined in the original MHEA field validation study .

4.3 Comparison of MHEA's estimated annual energy savings to the actual measured energy savings in each of the 43 mobile homes with high-quality data as determined in the original MHEA field validation study.

4.4 Comparison of MHEA's estimate of the pre-weatherization annual energy consumption to the actual measured energy consumption in each of the 43 mobile homes with highquality data after modifications were made to MHEA and changes were made in how some of the homes were modeled in MHEA.

4.5 Comparison of MHEA's estimate of the post-weatherization annual energy consumption to the actual measured energy consumption in each of the 43 mobile homes with highquality data after modifications were made to MHEA and changes were made in how some of the homes were modeled in MHEA.

4.6 Comparison of MHEA's estimated annual energy savings to the actual measured energy savings in each of the 43 mobile homes with high-quality data after modifications were made to MHEA and changes were made in how some of the homes were modeled in MHEA.... 16

4.7 Comparison of MHEA's estimate of the post-weatherization annual energy consumption to the actual measured energy consumption in each of the 43 mobile homes with high-quality data after modifications were made to MHEA, changes were made in how some of the homes were modeled in MHEA, and a 0.6 correction factor was applied to the energy saving calculations

4.8 Comparison of MHEA's estimated annual energy savings to the actual measured energy savings in each of the 43 mobile homes with high-quality data after modifications were made to MHEA, changes were made in how some of the homes were modeled in MHEA, and a 0.6 correction factor was applied to the energy saving calculations.

4.9 Comparison of MHEA's estimated annual energy savings to the actual measured energy savings in each of the 43 mobile homes with high-quality data after modifications were made to MHEA, changes were made in how some of the homes were modeled in MHEA, a 0.6 correction factor was applied to the energy saving calculations, and MHEA's billing adjustment feature was utilized 


\section{LIST OF TABLES}

ES.1 Comparison of MHEA and BESTEST space-heating loads ................................................ xiv

ES.2 Impacts of MHEA modifications on its overall predictive performance ..................................... $\mathrm{xV}$

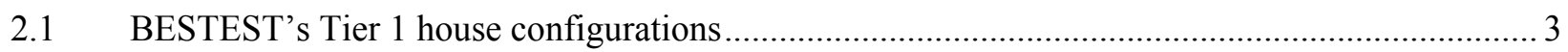

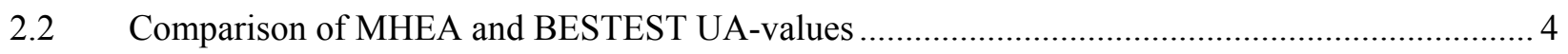

2.3 Comparison of MHEA and BESTEST space-heating loads .................................................. 6

3.1 Comparison of MHEA and RESNET space-heating energy consumptions ............................. 8

4.1 Impacts of MHEA modifications on its overall predictive performance .................................. 10

5.1 Summary of recommendations for the 18 Ohio mobile homes ................................................ 22 


\section{ACRONYMS}

$\begin{array}{ll}\text { AFUE } & \text { annual fuel utilization efficiency } \\ \text { BESTEST } & \text { Building Energy Simulation Test } \\ \text { DOE } & \text { Department of Energy } \\ \text { HERS } & \text { Home Energy Rating System } \\ \text { HSPF } & \text { heating seasonal performance factor } \\ \text { MHEA } & \text { Manufactured Home Energy Audit } \\ \text { NEAT } & \text { National Energy Audit Tool } \\ \text { RESNET } & \text { Residential Energy Services Network } \\ \text { SIR } & \text { savings-to-investment ratio } \\ \text { TMY } & \text { Typical Meteorological Year }\end{array}$




\section{ACKNOWLEDGEMENTS}

The authors would like to acknowledge the contributions made by the members of the Manufactured Home Energy Audit (MHEA) Steering Committee in the performance of this study. In addition to providing valuable comments and feedback on the individual analysis elements as they were performed, the committee provided an important, real-world reality check on the soundness of the final changes made to MHEA to true-up predictions to measured values. The members of the MHEA Steering Committee who contributed to this project are:

Tom Andrews, Ohio Energy Office

Dennis Biddle, Ohio Energy Office

James Childs, DOE

Robert DeSoto, DOE

Ted Koenig, Missouri Department of Natural Resources

Tim Lenahan, Ohio Energy Office

Dave Like, South Dakota Department of Social Services

Alex Moore, Simonson Management Services

Michael Peterson, DOE

Charlie Richardson, Longs Peak Energy Conservation

Gregg Riley, King County Housing Authority

Skip Sears, Missouri Ozarks Community Action

Bob Scott, West Virginia Governor's Office of Economic Opportunity

Cal Steiner, North Dakota Department of Commerce

Geoff Wilcox, Vermont Office of Economic Opportunity 


\section{EXECUTIVE SUMMARY}

Based on the results of a field validation study conducted in five states, the Manufactured Home Energy Audit (MHEA) was found to over predict the annual space-heating energy savings of weatherization measures to be installed in mobile homes by $186 \%$ on average, which led to an average realization rate (the actual savings divided by the predicted savings) of only $35 \%$. To determine the reasons for MHEA's over prediction of space-heating energy savings and to develop appropriate corrections to improve its performance, a series of analyses were performed.

The Home Energy Rating System (HERS) Building Energy Simulation Test (BESTEST) was used to evaluate the technical accuracy of MHEA's basic engineering calculations and modeling approach. BESTEST provides component UA-values and house space-heating loads for 15 configurations of a basic house that vary by insulation and infiltration levels, glazing properties and orientation, shading, internal loads, exterior surface color, and foundation types. Of the 15 test configurations, 10 were used in the analyses performed in this study (the remaining 5 configurations were not applicable to mobile homes).

The accuracy of MHEA's UA-value calculations was verified by comparing UA-values calculated by MHEA to values specified by BESTEST. After minor adjustments were made to some of the R-value assumptions and algorithms used in MHEA, the final UA-values calculated by MHEA were found to be within $11 \%$ of the values reported by BESTEST for 7 of the 13 envelope variations that could be studied ( 2 infiltration levels, 3 ceiling insulation levels, 3 wall insulation levels, 2 floor insulation levels, 2 grades of windows, and 1 grade of doors), and were off between 20 and $75 \%$ in the remaining 6 cases.

Deviations of more than 20\% from BESTEST occurred not because MHEA's calculations were wrong, but because (a) the BESTEST basic house is a site-built home that could not be perfectly modeled in MHEA (i.e., MHEA's calculations were accurately reflecting mobile home rather than site-built, singlefamily construction); (b) a wood-framed, argon-filled window was not an available option in MHEA; and (c) infiltration UA-values in MHEA were purposefully less than theoretical values based on previous field research and user input (and will be further reduced as will be explained below).

Once the accuracy of MHEA's UA-value calculations were confirmed, the accuracy of MHEA's spaceheating load calculations were studied by comparing MHEA's estimated loads to BESTEST's loads for each of the 10 test configurations. In performing this analysis, the input to MHEA was modified so that the UA-values calculated by MHEA for each of the envelope components were equal to the UA-values specified by BESTEST. By performing the analysis in this way, the accuracy of MHEA's variable-based degree-day heating load calculation method was isolated from the accuracy of the UA-value calculations.

Table ES.1 shows that MHEA's space-heating energy loads passed the BESTEST criteria for each of the 10 test configurations. BESTEST's loads are based on modeling each of the test configurations in three different hourly simulation programs that are widely accepted within the engineering profession as being accurate: BLAST, DOE-2, and SERI-RES. Thus, it should be stressed that this analysis of the accuracy of MHEA's space-heating energy load calculations is based on a comparison with loads calculated by other simulation programs rather than to measurements of actual loads in real houses.

Given that MHEA accurately calculated envelope UA-values and space-heating loads, MHEA's ability to accurately calculate the space-heating energy consumption of different space-heating systems was then examined using the Procedures for Verification of RESNET Accredited HERS Software Tools. To pass, the percentage change in space-heating energy consumptions for the following systems must be within specified ranges: a gas furnace with a 90\% annual fuel utilization efficiency (AFUE) compared with a $78 \%$ AFUE gas furnace, a heat pump with a 9.85 heating seasonal performance factor (HSPF) compared with a 6.8 HSPF heat pump, and an electric resistance furnace compared with the 6.8 HSPF heat pump. 
Initial results indicated that MHEA's calculations for heat pumps were not correct. MHEA was therefore changed using equations to account for climate impacts on HSPF. This corrected version of MHEA was then found to accurately calculate the changes in space-heating energy consumptions specified by RESNET. The RESNET procedure was based on modeling results using six detailed hourly simulation programs: two DOE-2.1E tools, two DOE-2.2 tools, Micropas version 6.5, and TRNSYS version 15.

Table ES.1. Comparison of MHEA and BESTEST space-heating loads

\begin{tabular}{|c|c|c|c|c|c|c|}
\hline \multirow{3}{*}{$\begin{array}{c}\text { Test } \\
\text { configuration }\end{array}$} & \multicolumn{3}{|c|}{$\begin{array}{c}\text { Annual space-heating load } \\
\text { (MBtu) }\end{array}$} & \multicolumn{3}{|c|}{$\begin{array}{c}\text { Change in annual space-heating load } \\
\text { compared with a base case } \\
\text { (MBtu) }\end{array}$} \\
\hline & \multicolumn{2}{|c|}{ BESTEST } & \multirow[b]{2}{*}{ MHEA } & \multicolumn{2}{|c|}{ BESTEST } & \multirow[b]{2}{*}{ MHEA } \\
\hline & Maximum & Minimum & & Maximum & Minimum & \\
\hline L L100A & 79.48 & 48.75 & 64.3 & & & \\
\hline L110A & 103.99 & 71.88 & 86.9 & 28.12 & 19.36 & 22.6 \\
\hline L120A & 64.3 & 37.82 & 53.6 & -7.67 & -18.57 & -10.7 \\
\hline L130A & 53.98 & 41.82 & 43.7 & -5.97 & -27.5 & -20.6 \\
\hline L140A & 56.48 & 43.24 & 50.1 & -4.56 & -24.42 & -14.2 \\
\hline L150A & 71.33 & 40.95 & 54.2 & -3.02 & -12.53 & -10.1 \\
\hline L155A & 74.18 & 43.53 & 57.0 & 6.88 & -1.54 & 2.8 \\
\hline L160A & 81.00 & 48.78 & 63.7 & 5.1 & -3.72 & -0.6 \\
\hline L170A & 92.40 & 61.03 & 74.3 & 17.64 & 7.12 & 10.0 \\
\hline L200A & 185.87 & 106.41 & $136.3^{*}$ & 107.66 & 56.39 & $72.0^{*}$ \\
\hline
\end{tabular}

*MHEA's UA-value for the floor $\left(299.2 \mathrm{Btu} / \mathrm{h}^{\circ} \mathrm{F}\right)$ could not be made equal to BESTEST's UA-value (363.3 $\left.\mathrm{Btu} / \mathrm{h} \cdot{ }^{\circ} \mathrm{F}\right)$. The space-heating energy load and change in load would have been slightly higher if the correct UAvalue could have been entered.

Even though MHEA was shown to be accurate when compared with other computer models, modifications were made to MHEA to true-up its predictions of space-heating energy consumptions and savings to values measured in the original field validation. Table ES.2 shows that the version of MHEA used in the field validation over predicted the space-heating energy savings by $186 \%$ and achieved a realization rate of $35 \%$ in a subset of 43 homes with high-quality data (i.e., high-quality homes) and considering supplemental electric space-heating. The table also shows that the impact of the changes described above in MHEA's R-value assumptions and UA calculations on its overall performance was small: MHEA's over prediction of space-heating energy savings was still $163 \%$ and the realization rate was $38 \%$.

Initially, three engineering-based modifications to MHEA were identified:

- The internal loads assumed in MHEA for appliances and two adult occupants were changed from $2400 \mathrm{Btu} / \mathrm{h}$ during the day and $1000 \mathrm{Btu} / \mathrm{h}$ at night to $1950 \mathrm{Btu} / \mathrm{h}$ and $2350 \mathrm{Btu} / \mathrm{h}$, respectively.

- The load MHEA calculates for infiltration from blower door readings was reduced by about $25 \%$.

- An R-value of 1 was added to the ceiling, floor, and walls in calculating the UA-value of these envelope components.

In addition, two changes were made to how a few of the 43 homes with high-quality data were modeled in MHEA: MHEA was configured to estimate no savings for programmable thermostats installed in 5 of the 43 homes, and the amount of floor insulation was increased in 6 of the 43 homes from 0 to 0.5 in. These changes were made so that the selection of modifications to MHEA to true-up predictions to measured values and the success or failure of these modifications would not be based on unused programmable thermostats or on possibly incorrect input data. 
Table ES.2. Impacts of MHEA modifications on its overall predictive performance

\begin{tabular}{|c|c|c|c|c|c|c|c|c|}
\hline \multirow[b]{3}{*}{ Houses } & \multicolumn{4}{|c|}{ Without supplemental electricity use* } & \multicolumn{4}{|c|}{ With supplemental electricity use* } \\
\hline & \multicolumn{3}{|c|}{ MHEA over-prediction } & \multirow{2}{*}{$\begin{array}{c}\text { Realization } \\
\text { rate }\end{array}$} & \multicolumn{3}{|c|}{ MHEA over-prediction } & \multirow{2}{*}{$\begin{array}{c}\text { Realization } \\
\text { rate }\end{array}$} \\
\hline & Pre & Post & Savings & & Pre & Post & Savings & \\
\hline \multicolumn{9}{|c|}{ Original MHEA Field Validation Study: } \\
\hline $\begin{array}{l}\text { All houses ( } 86 \\
\text { pre, } 72 \text { post) }\end{array}$ & $33 \%$ & $-2 \%$ & $196 \%$ & $34 \%$ & & & & \\
\hline $\begin{array}{l}\text { High-quality } \\
\text { houses ( } 43)\end{array}$ & $44 \%$ & $2 \%$ & $191 \%$ & $34 \%$ & $33 \%$ & $-7 \%$ & $186 \%$ & $35 \%$ \\
\hline \multicolumn{9}{|c|}{ After UA-Calculation Modifications: } \\
\hline $\begin{array}{l}\text { High-quality } \\
\text { houses (43) }\end{array}$ & $35 \%$ & $-3 \%$ & $168 \%$ & $37 \%$ & $24 \%$ & $-12 \%$ & $163 \%$ & $38 \%$ \\
\hline \multicolumn{9}{|c|}{ Following Engineering Modifications and Modeling Changes: } \\
\hline $\begin{array}{l}\text { High-quality } \\
\text { houses (43) }\end{array}$ & $16 \%$ & $-12 \%$ & $113 \%$ & $47 \%$ & $6 \%$ & $-20 \%$ & $109 \%$ & $48 \%$ \\
\hline $\begin{array}{l}\text { High-quality } \\
\text { houses and } \\
\text { eliminating } \\
\text { "zero" energy } \\
\text { savers (35) }\end{array}$ & & & $66 \%$ & $60 \%$ & & & $61 \%$ & $62 \%$ \\
\hline \multicolumn{9}{|c|}{ After 0.6 Correction Factor Applied to Energy Savings: } \\
\hline $\begin{array}{l}\text { High-quality } \\
\text { houses (43) }\end{array}$ & $16 \%$ & $12 \%$ & $28 \%$ & $79 \%$ & $6 \%$ & $1 \%$ & $25 \%$ & $80 \%$ \\
\hline \multicolumn{9}{|c|}{ Using MHEA's Billing Adjustment Feature: } \\
\hline $\begin{array}{l}\text { High-quality } \\
\text { houses (43) }\end{array}$ & $16 \%$ & $15 \%$ & $16 \%$ & $87 \%$ & $6 \%$ & $4 \%$ & $14 \%$ & $88 \%$ \\
\hline
\end{tabular}

*Supplemental space-heating electricity use was determined for homes heated primarily by natural gas or propane from a PRISM analysis of the electric billing data. For homes in which natural gas or propane was the primary space-heating fuel, the actual space-heating energy consumption was calculated in two ways: (a) based only on the primary space-heating fuel consumption (i.e., on the natural gas or propane consumption without including the supplemental electricity use); and (b) by adding the supplemental space-heating electricity use to the natural gas or propane space-heating consumption.

As shown in Table ES.2, the overall impact of these modifications and modeling changes was to reduce the over prediction of space-heating energy savings from $163 \%$ to $109 \%$ and increase the realization rate from $38 \%$ to $48 \%$. Pre-weatherization space-heating energy consumption predictions and energy savings estimates were greatly improved despite the decreased accuracy in post-weatherization space-heating energy consumption predictions. Improvements were seen especially in homes with little or no insulation and/or high infiltration before weatherization, and in homes whose estimates of pre-weatherization energy consumption and/or energy savings deviated the most from actual values before the modifications and changes were made.

Since no further valid engineering-based modifications could be identified to finish truing-up MHEA's predicted savings to measured values, MHEA was modified to multiply the space-heating energy savings of all measures by a 0.6 correction factor (i.e., reducing the energy savings by $40 \%$ ) to complete the truing-up process. By incorporating this 0.6 correction factor into MHEA's space-heating energy savings calculations, MHEA's post-weatherization space-heating energy consumptions were improved to be within $1 \%$ of actual, the over prediction of space-heating energy savings was reduced from $109 \%$ to just $25 \%$, and the realization rate was increased from $48 \%$ to $80 \%$ (the correction factor had no effect on MHEA's pre-weatherization space-heating energy consumption predictions, which remained within $6 \%$ of actual). These results are shown in Table ES.2. 


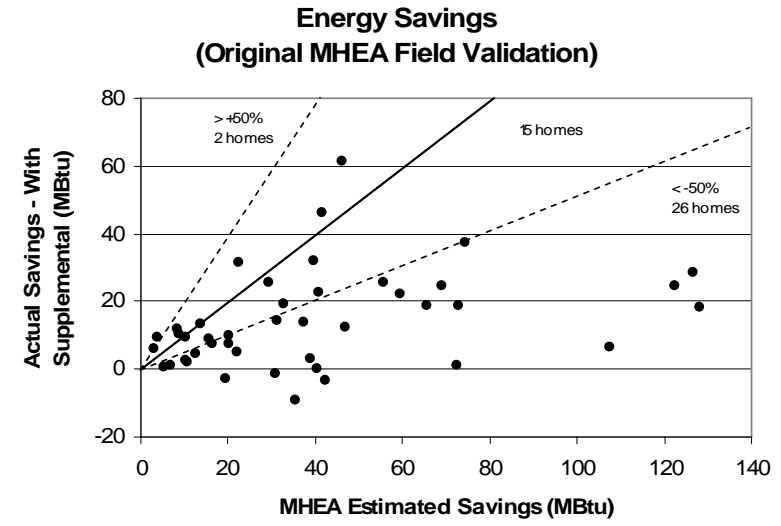

(a)

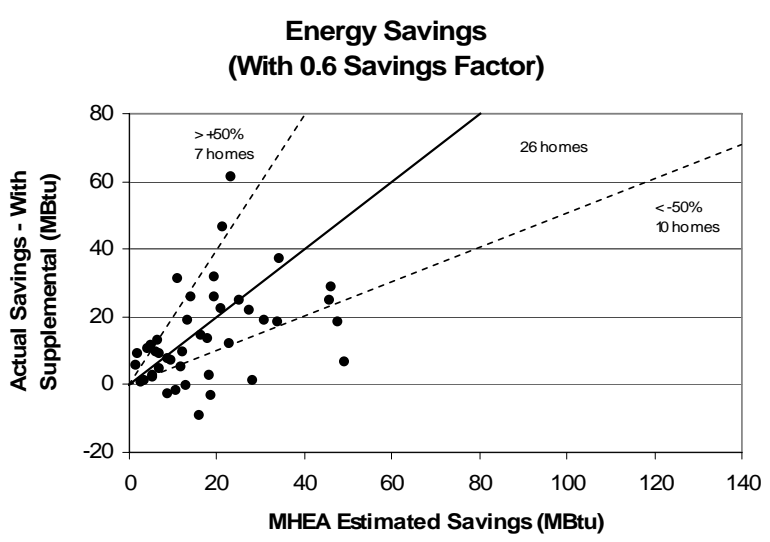

(b)

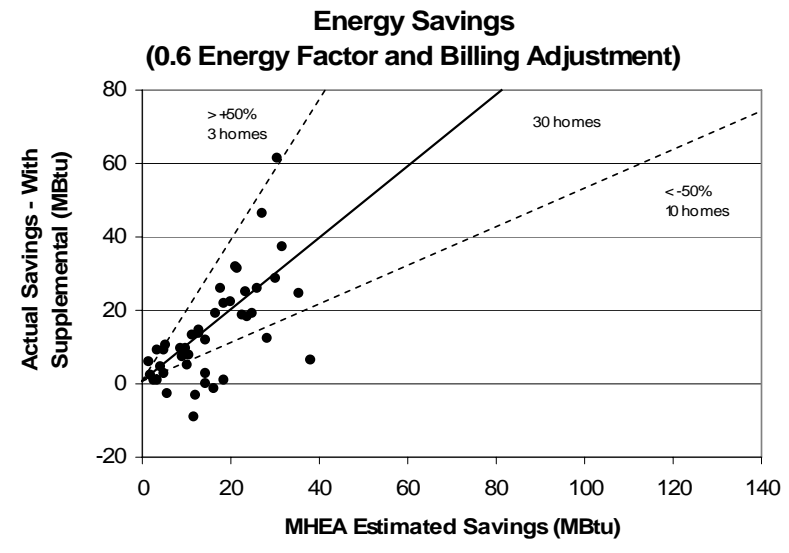

(c)

Fig. ES.1. Comparison of MHEA's estimated annual energy savings to the actual measured energy savings in each of the 43 mobile homes with high-quality data as determined (a) in the original MHEA field validation study, (b) after modifications and a 0.6 correction factor were incorporated into MHEA, and (c) after MHEA's billing adjustment feature was used together with the modifications and 0.6 correction factor. The solid line shows equivalency between actual and estimated energy savings, and the dashed lines show deviations in estimated savings from actual by $+/-50 \%$.

Figure ES.1 shows the improvement obtained in MHEA's prediction of space-heating energy savings from the modifications and correction factor described above. The over prediction of energy savings for the version of MHEA used in the original field validation is evident in Fig. ES.1(a), as MHEA over predicted the space-heating energy savings by more than $50 \%$ in 26 homes ( $60 \%$ of the homes). The reduction in MHEA's space-heating energy saving estimates (the shift of the homes to the left) and the better clustering of homes around the line of equivalency are evident in Fig. ES.1(b), which shows results after the modifications and correction factor were incorporated into MHEA.

MHEA includes an optional billing adjustment feature that adjusts its annual energy savings estimates of measures based on pre-weatherization billing data (if entered). In the original MHEA validation study, the use of MHEA's billing adjustment feature reduced the over prediction of space-heating energy savings by over $50 \%$ (from $186 \%$ to $88 \%$ ) and increased the realization rate from $35 \%$ to $53 \%$; thus, the billing adjustment feature alone was unable to fully correct MHEA's predictions. Once MHEA's performance was improved through the implementation of the engineering modifications and correction factor, use of 
MHEA's billing adjustment feature reduced MHEA's over prediction of space-heating energy savings from $25 \%$ to just $14 \%$ and increased its realization rate from $80 \%$ to $88 \%$ (see Table ES.2).

Since the billing adjustment feature tended to reduce MHEA's space-heating energy savings prediction in homes in which the savings was being over predicted and to increase MHEA's prediction in homes in which the savings was being under predicted, the billing adjustment not only improved MHEA's overall performance, but also improved MHEA's performance in most individual homes. This is evident from comparing Fig. ES.1(c) to Fig. ES.1(b). Individual homes are grouped much more closely around the line of equivalency, and movement toward the line of equivalency occurred in homes in which MHEA was under predicting savings as well as in homes in which it was over predicting savings.

The impact of using the revised version of MHEA on a weatherization program was investigated using 18 mobile homes from the original MHEA validation study. It was found that use of the revised version of MHEA would not automatically result in the wholesale elimination of cost-effective weatherization measure recommendations in mobile homes. Fewer storm windows might be recommended (a change that many weatherization professionals might agree with), but recommendations for ceiling, wall, and floor insulation would still be prevalent (especially as agencies learn how to reduce the installation costs). Average investment levels per home may drop some, eliminating the installation of measures that are not cost effective and freeing-up funds to allow cost-effective measures to be installed in more homes.

This study produced the following conclusions:

- MHEA appropriately reflects mobile home construction and accurately calculates the UA-values of mobile home envelope components.

- MHEA's variable-based degree-day load calculation method accurately calculates space-heating energy loads if the correct UA-values and other input are used.

- MHEA accurately calculates the space-heating energy consumption for gas furnaces, heat pumps, and electric-resistance furnaces if the space-heating load and other input are accurate.

- Even though MHEA's calculations were shown to be correct from an engineering point of view, three modifications to MHEA's algorithms and use of a 0.6 correction factor are needed to true-up predicted savings to savings measured in the houses used in the recent MHEA field validation.

- A revised version of MHEA would still recommend a significant number of cost-effective weatherization measures in mobile homes (including ceiling, floor, and even wall insulation and far fewer storm windows).

Based on these findings and conclusions, it was recommended that:

- A revised version of MHEA with all the changes and modifications outlined in this report should be finalized and made available to the weatherization community as soon as possible, preferably in time for use within the 2009 Program Year.

- The accuracy of MHEA's space-cooling energy load and consumption predictions should be analyzed using the same HERS BESTEST and RESNET procedures used for space-heating.

- To verify the accuracy of MHEA's space-cooling predictions, a field test should be performed so that predicted space-cooling energy consumptions and savings can be compared with measured values. 
xviii 


\begin{abstract}
A series of analyses were performed to determine the reasons that the Manufactured Home Energy Audit (MHEA) over predicted space-heating energy savings as measured in a recent field test and to develop appropriate corrections to improve its performance. The study used the Home Energy Rating System (HERS) Building Energy Simulation Test (BESTEST) to verify that MHEA accurately calculates the UAvalues of mobile home envelope components and space-heating energy loads as compared with other, well-accepted hourly energy simulation programs. The study also used the Procedures for Verification of RESNET Accredited HERS Software Tools to determine that MHEA accurately calculates space-heating energy consumptions for gas furnaces, heat pumps, and electric-resistance furnaces. Even though MHEA's calculations were shown to be correct from an engineering point of view, three modifications to MHEA's algorithms and use of a 0.6 correction factor were incorporated into MHEA to true-up its predicted savings to values measured in a recent field test. A simulated use of the revised version of MHEA in a weatherization program revealed that MHEA would likely still recommend a significant number of cost-effective weatherization measures in mobile homes (including ceiling, floor, and even wall insulation and far fewer storm windows). Based on the findings from this study, it was recommended that a revised version of MHEA with all the changes and modifications outlined in this report should be finalized and made available to the weatherization community as soon as possible, preferably in time for use within the 2009 Program Year.
\end{abstract}




\section{INTRODUCTION}

The Weatherization Assistant is an energy audit program developed for use within the U.S Department of Energy's (DOE's) Weatherization Assistant Program. The Weatherization Assistant is an umbrella program for two separate energy audits: the National Energy Audit Tool (NEAT) for site-built singlefamily houses and the Manufactured Home Energy Audit (MHEA) for mobile homes.

Based on the results of the MHEA field validation study (Ternes 2007), MHEA was found to over predict the annual space-heating energy savings of weatherization measures to be installed in mobile homes by $186 \%$ on average, which led to an average realization rate of only $35 \%$. This field validation tested Version 7.4 of MHEA and involved monitoring a total of 86 mobile homes from the following 5 states: North Dakota, Wisconsin, Ohio, Missouri, and Virginia. To determine the reasons for MHEA's over prediction of space-heating energy savings and to develop appropriate corrections to improve its performance, four analyses were performed:

- The technical accuracy of MHEA's basic engineering calculations and modeling approach was evaluated using the Home Energy Rating System (HERS) Building Energy Simulation Test (BESTEST) (Judkoff and Neymark 1995). This included an examination of the ceiling, wall, floor, window, door, and infiltration UA-values calculated by MHEA for 10 different house configurations as well as the total space-heating load calculated by MHEA for these house configurations.

- MHEA's ability to accurately calculate space-heating energy consumptions from space-heating loads for three different space-heating systems (gas furnace, electric resistance furnace, and heat pump) was examined using the Procedures for Verification of RESNET Accredited HERS Software Tools (RESNET 2006).

- Engineering-based modifications and other corrections needed to reduce MHEA's over prediction of space-heating energy savings were identified and verified using the mobile homes from the original MHEA validation study.

- The impact of using the revised version of MHEA on a weatherization program was investigated using 18 mobile homes from the original MHEA validation study.

Version 8.3 of MHEA was used in these four analyses. The primary changes made to Version 8 were the addition of administration features that would be useful in running a weatherization program, such as the ability to develop work orders and track the status of jobs. Although there were some technical enhancements made in Version 8, it was believed that these changes would not significantly affect the overall field validation results. After the 86 homes used in the field validation were entered into Version 8.3 , a comparison of space-heating energy consumptions and savings to the original Version 7.4 results confirmed that there were no appreciable differences between the two versions.

The analyses presented in this report focus only on space-heating. The MHEA field validation did not address air conditioning energy consumption; thus, it provides no information on MHEA's performance in predicting space-cooling energy savings. It was decided to focus the analyses presented in this report on investigating and improving MHEA's space-heating energy savings predictions, leaving an analysis of MHEA's space-cooling performance for later.

\footnotetext{
${ }^{1}$ The realization rate is the actual savings divided by the predicted savings.
} 


\section{BESTEST ANALYSES}

BESTEST's tests use a basic single-family, site-built house. Although MHEA is designed specifically to model mobile homes, the site-built house used in BESTEST is simplistic enough (e.g., rectangular shape, unfinished attic) that it could be reasonably modeled by MHEA. As part of BESTEST's Tier 1 tests, 15 configurations of the basic house are employed to test building energy software with respect to different insulation and infiltration levels, glazing properties and orientation, shading, internal loads, exterior surface color, and foundations (see Table 2.1). However, only 10 of the 15 test configurations were used in this analysis. BESTEST's test configurations L302A to L324A were not used because MHEA cannot model slab or basement foundations (BESTEST's test configurations L100A to L202A assume a crawlspace, which can be reasonably modeled by MHEA). In addition, BESTEST's test configuration L202A was not used in this analysis because exterior wall surface color/solar absorptance is not an input in MHEA. Nor were BESTEST's Tier 2 tests, which employ six additional configurations of the basic house, used in this analysis because they focus on additional elements related to passive solar design, which is irrelevant to MHEA.

Table 2.1. BESTEST's Tier 1 house configurations

\begin{tabular}{|c|l|}
\hline $\begin{array}{c}\text { Test } \\
\text { configuration }\end{array}$ & \multicolumn{1}{c|}{ Description } \\
\hline \hline L100A & $\begin{array}{l}\text { Base home: crawl space foundation; typical infiltration rate, insulation levels, and } \\
\text { internal loads; and single-pane windows evenly distributed on exterior walls with } \\
\text { no shading }\end{array}$ \\
\hline L110A & Higher infiltration rate \\
\hline L120A & Higher wall and ceiling insulation levels \\
\hline L130A & Better windows \\
\hline L140A & No windows \\
\hline L150A & All windows on south wall \\
\hline L155A & All windows on south wall with shading provided by an overhang \\
\hline L160A & All windows on east and west walls \\
\hline L170A & No internal loads \\
\hline L200A & Lower floor, wall, and ceiling insulation levels, and higher infiltration rate \\
\hline L202A & Exterior surface color with low solar absorptance \\
\hline L302A & Uninsulated slab \\
\hline L304A & Insulated slab \\
\hline L322A & Uninsulated basement \\
\hline L324A & Insulated basement \\
\hline
\end{tabular}

\subsection{VERIFICATION OF UA CALCULATIONS}

The first analysis performed was to verify the accuracy of MHEA's UA-value calculations by comparing UA-values calculated by MHEA with values specified by BESTEST. BESTEST documentation provides construction details, R-values of construction materials, and UA-values for the main envelope components (ceiling, walls, floor, windows, doors, and infiltration) for all the test configurations outlined in Table 2.1. Each test configuration was entered into MHEA based on the construction details provided, and then the UA-values calculated initially by MHEA were compared with those reported by BESTEST. Table 2.2 shows the UA-values for the base home and 3 additional test configurations that capture all the variations in UA-values offered by the 10 test configurations (e.g., the higher additional infiltration tested by configuration L110A was also tested in configuration L200A). 
The R-values of construction materials used in MHEA were compared with BESTEST values as well as values published in the literature (e.g., ASHRAE 2001). As a result, minor adjustments were made to some of the values (see Appendix A). In addition, the MHEA algorithms used to calculate component UA-values were examined and modified as needed (see Appendix A). Some of the changes to the algorithms were made to correct minor errors, while other changes were made to bring more consistency to the calculations within MHEA or between MHEA and NEAT. Each test configuration was then rerun using the new R-values and UA algorithms that had been entered into MHEA. The final UA-values calculated by MHEA are shown in Table 2.2.

Table 2.2. Comparison of MHEA and BESTEST UA-values

\begin{tabular}{|c|c|c|c|c|c|}
\hline \multirow{2}{*}{$\begin{array}{c}\text { Test } \\
\text { configuration }\end{array}$} & \multirow[b]{2}{*}{ Description } & \multirow{2}{*}{$\begin{array}{c}\text { Envelope } \\
\text { component }\end{array}$} & \multicolumn{3}{|c|}{ UA-value $\left(\right.$ Btu/h/h $\left.{ }^{\cdot 0} \mathbf{F}\right)$} \\
\hline & & & BESTEST & MHEA - initial & MHEA - final \\
\hline \multirow{6}{*}{ L100A } & \multirow{6}{*}{ Base home } & Floor & 108.8 & 109.8 & 100.2 \\
\hline & & Walls & 87.9 & 95.8 & 97.2 \\
\hline & & Ceiling & 75.1 & 77.5 & 81.2 \\
\hline & & Windows & 280.4 & 297.0 & 251.1 \\
\hline & & Doors & 13.2 & $10.3^{*}$ & 11.9 \\
\hline & & Infiltration & 118.2 & $67.9^{*}$ & $67.9^{*}$ \\
\hline \multirow{2}{*}{ L120A } & \multirow{2}{*}{$\begin{array}{l}\text { More wall and } \\
\text { ceiling insulation }\end{array}$} & Walls & 43.8 & 42.5 & 43.3 \\
\hline & & Ceiling & 25.9 & $37.9^{*}$ & $45.5^{*}$ \\
\hline L130A & Better windows & Windows & 81.0 & $156.6^{*}$ & $119.8^{*}$ \\
\hline \multirow{4}{*}{ L200A } & \multirow{4}{*}{$\begin{array}{l}\text { Less floor, wall, } \\
\text { and ceiling } \\
\text { insulation, and } \\
\text { higher infiltration }\end{array}$} & Floor & 363.3 & $306.4^{*}$ & $284.3^{*}$ \\
\hline & & Walls & 213.7 & $425.9^{*}$ & $357.8^{*}$ \\
\hline & & Ceiling & 114.3 & 113.6 & 116.2 \\
\hline & & Infiltration & 264.5 & $170.1^{*}$ & $170.1^{*}$ \\
\hline
\end{tabular}

*MHEA's UA-values deviate from BESTEST values by more than $15 \%$. All other UA-values are within $11 \%$ of BESTEST.

The final UA-values calculated by MHEA were within $11 \%$ of the values reported by BESTEST for 7 of the 13 envelope variations that could be studied, and were off between 20 and $75 \%$ in the remaining 6 cases. The primary reason that MHEA was off by more than $20 \%$ is because BESTEST's site-built home could not be perfectly modeled in MHEA, which is designed specifically to model mobile homes.

Detailed explanations for the observed deviations are provided below:

- Floor-The floor in BESTEST test configuration L100A was insulated with an R-11 fiberglass batt attached to the underside of the floor, with the underside of the insulation exposed to the air in the crawlspace, while the floor in configuration L200A was uninsulated, so that the underside of the floor was exposed to crawlspace air. In mobile homes, the use of a belly wrap or rodent barrier installed on the underside of the floor joists creates an air space between the belly wrap/rodent barrier and the underside of the floor (or the underside of any insulation installed flush to the floor), which increases the R-value of the floor assembly. MHEA always assumes that this air space is present unless the cavity is full of insulation. Thus, the R-value of the floor calculated by MHEA will be higher than BESTEST, which results in a lower UA-value. Although the added R-value of the air cavity of about 1 as calculated by MHEA has a rather small impact on the total UA-value of the floor when R-11 insulation is installed (test configuration L100A), it has a significant impact on the total UA-value of the floor when the floor is uninsulated (test configuration L200A).

- Walls-The walls in all the BESTEST configurations had fiberboard sheathing and hardboard siding, which adds an R-value of about 2 to the wall assembly. In mobile homes, sheathing is typically not present and the exterior siding is a thin sheet of metal having a negligible R-value. Thus, the R-value of the walls calculated by MHEA will be lower than BESTEST, which results in a higher UA-value. 
Although the decreased R-value of about 2 has a negligible impact on the total UA-value of the wall when R-19 insulation and insulated sheathing are installed (test configuration L120A) and a rather small impact when R-11 insulation is installed (test configuration L100A), it has a significant impact on the total UA-value of the wall when the wall is uninsulated (test configuration L200A).

- Ceiling-The ceilings in all the BESTEST configurations were unfloored attics under a pitched roof. Therefore, in MHEA, its "pitched roof" ceiling type was used. MHEA accounts for less insulation installed at the perimeter of a ceiling under a pitched roof because of the low pitch found in mobile homes and the lack of a significant heel at the perimeter, whereas BESTEST assumes that the specified insulation level is uniform across the ceiling. Therefore, MHEA will calculate a lower Rvalue and a higher UA-value for the ceiling assembly, especially as insulation levels increase.

- Windows-The windows in test configuration L100A are single-pane, aluminum frame with a thermal break. The overall R-value specified in BESTEST for these windows is very close to values reported by ASHRAE (2001) based on a $15 \mathrm{mph}$ wind. However, ASHRAE states that these values should be used only for design purposes (e.g., to calculate design heating load) and not for more general load calculations because $15 \mathrm{mph}$ winds are not experienced continuously. Therefore, the R-values used in MHEA are ASHRAE values that have been "corrected" following ASHRAE procedures to $0 \mathrm{mph}$, which results in a slightly higher R-value for the windows and a slightly lower UA-value.

The windows in test configuration L130A are double-pane, low-e, and argon filled with a wood frame. MHEA has no options for argon-filled or wood frame windows. Therefore, MHEA's R-value for these windows when entered as best as possible is significantly less than BESTEST's, which results in a significantly higher UA-value.

- Infiltration-The MHEA algorithms that calculate the infiltration heating load from blower door readings and, hence, an effective infiltration UA-value are purposely designed to include correction factors that reduce the heating load and, thus, the effective UA-value from theoretical values. These correction factors have been incorporated based on previous field research and user input. As will be discussed in Sect. 4, later analyses led to the inclusion of an additional correction factor in MHEA that further reduces the infiltration heating load and effective UA-value.

The conclusion reached from this analysis of UA-values is that MHEA with the minor corrections made accurately calculates the UA-values of mobile home envelope components. Deviations from BESTEST occur not because MHEA's calculations are wrong, but either because of MHEA's focus on mobile home (as opposed to site-built) construction or some other reason.

\subsection{VERIFICATION OF SPACE-HEATING LOAD CALCULATIONS}

Once the accuracy of MHEA's UA-value calculations were confirmed, the next analysis performed was to verify the accuracy of MHEA's space-heating load calculations by comparing MHEA's estimated loads to BESTEST's loads for each of the test configurations outlined in Table 2.1. MHEA uses a variable-based degree-day method to translate UA-values and other input into space-heating loads. The analysis was designed to focus on the accuracy of the variable-based degree-day method itself rather than combined with the UA-value calculations because the accuracy of MHEA's UA-value calculations had already been established through a separate analysis (see Sect. 2.1).

Each test configuration outlined in Table 2.1 was again entered into MHEA based on the construction details provided. The input was then modified so that the UA-values calculated by MHEA for each of the envelope components were equal to the UA-values specified by BESTEST. For example, even though MHEA's calculation of the ceiling insulation UA-value is greater than BESTEST's value for a given R- 
value of insulation, the R-value in MHEA was increased beyond that specified by BESTEST until MHEA's UA-value equaled BESTEST's' UA-value. Once MHEA's UA-values were made equivalent to BESTEST specified values, the heating load calculated by MHEA for each test configuration was then compared with the heating load specified by BESTEST. Climate data for Colorado Springs, Colorado, is used for this analysis as required by BESTEST. ${ }^{2}$ By performing the analysis in this way, the accuracy of MHEA's variable-based degree-day method was isolated because the UA-values and other input were exactly equal to that specified by BESTEST.

MHEA's estimated space-heating loads are compared with BESTEST's loads in Table 2.3. BESTEST's loads are based on modeling each of the test configurations in three different hourly simulation programs that are widely accepted within the engineering profession as being accurate: BLAST, DOE-2, and SERIRES. Thus, it should be stressed that this analysis of the accuracy of MHEA's space-heating energy load calculations is based on a comparison with loads calculated by other simulation programs rather than with measurements of actual loads in real houses. To pass the BESTEST criteria, the absolute value of the space-heating load calculated by MHEA for each test configuration must be within a given range. The change in space-heating load compared with a base case must also be within a given range. Test configuration L100A is the base case for all other test configurations except for test configuration L155A which is compared with test configuration L150A.

Table 2.3 shows that MHEA's space-heating energy load and change in load passed the BESTEST criteria for each of the 10 test configurations. In fact, MHEA's energy loads were very consistent with those calculated by BLAST for each of the 10 test configurations and were generally about 3-9 MBtu higher than those calculated by DOE-2. Therefore, the conclusion reached from this analysis is that MHEA's variable-based degree-day method accurately calculates space-heating energy loads if the correct UA-values and other input are used.

Table 2.3. Comparison of MHEA and BESTEST space-heating loads

\begin{tabular}{|c|c|c|c|c|c|c|}
\hline \multirow{3}{*}{$\begin{array}{c}\text { Test } \\
\text { configuration } \\
\end{array}$} & \multicolumn{3}{|c|}{$\begin{array}{c}\text { Annual space-heating load } \\
\text { (MBtu) }\end{array}$} & \multicolumn{3}{|c|}{$\begin{array}{c}\text { Change in annual space-heating load } \\
\text { compared with a base case } \\
\text { (MBtu) }\end{array}$} \\
\hline & \multicolumn{2}{|c|}{ BESTEST } & \multirow[b]{2}{*}{ MHEA } & \multicolumn{2}{|c|}{ BESTEST } & \multirow[b]{2}{*}{ MHEA } \\
\hline & Maximum & Minimum & & Maximum & Minimum & \\
\hline L100A & 79.48 & 48.75 & 64.3 & & & \\
\hline L110A & 103.99 & 71.88 & 86.9 & 28.12 & 19.36 & 22.6 \\
\hline L120A & 64.3 & 37.82 & 53.6 & -7.67 & -18.57 & -10.7 \\
\hline L130A & 53.98 & 41.82 & 43.7 & -5.97 & -27.5 & -20.6 \\
\hline L140A & 56.48 & 43.24 & 50.1 & -4.56 & -24.42 & -14.2 \\
\hline L150A & 71.33 & 40.95 & 54.2 & -3.02 & -12.53 & -10.1 \\
\hline $\mathrm{L} 155 \mathrm{~A}$ & 74.18 & 43.53 & 57.0 & 6.88 & -1.54 & 2.8 \\
\hline L160A & 81.00 & 48.78 & 63.7 & 5.1 & -3.72 & -0.6 \\
\hline L170A & 92.40 & 61.03 & 74.3 & 17.64 & 7.12 & 10.0 \\
\hline L200A & 185.87 & 106.41 & $136.3 *$ & 107.66 & 56.39 & $72.0^{*}$ \\
\hline
\end{tabular}

*MHEA's UA-value for the floor $\left(299.2 \mathrm{Btu} / \mathrm{h} \cdot{ }^{\circ} \mathrm{F}\right)$ could not be made equal to BESTEST's UA-value (363.3 $\left.\mathrm{Btu} / \mathrm{h} \cdot{ }^{\circ} \mathrm{F}\right)$. The space-heating energy load and change in load would have been slightly higher if the correct UAvalue could have been entered.

\footnotetext{
${ }^{2}$ The weather data for Colorado Springs provided with MHEA was used rather than the Typical Meteorological Year (TMY) weather data provided by BESTEST. However, MHEA's weather data are based on TMY weather data. The heating degree hours for both data sets were identical.
} 


\section{RESNET ANALYSIS}

Given that MHEA accurately calculates envelope UA-values and space-heating loads, MHEA's ability to accurately estimate the space-heating energy consumption of different space-heating systems was then verified. This analysis was performed using the Procedures for Verification of RESNET Accredited HERS Software Tools.

The RESNET procedures require that the space-heating energy consumption of the BESTEST base house (test configuration L100A) be calculated for a gas furnace with an annual fuel utilization efficiency (AFUE) of $78 \%$ and $90 \%$, an air source heat pump with a heating seasonal performance factor (HSPF) of 6.8 and 9.85, and an electric resistance furnace with a coefficient of performance (COP) of 1.0 (essentially equivalent to an efficiency of $100 \%$ ). To pass the RESNET procedures, the percentage change in the following space-heating energy consumptions must be calculated and be within the ranges specified in Table 3.1: the 90\% AFUE gas furnace is compared with the 78\% AFUE gas furnace, the $9.85 \mathrm{HSPF}$ heat pump is compared with the 6.8 HSPF heat pump, and the electric resistance furnace is compared with the 6.8 HSPF heat pump. The actual space-heating energy consumptions of the base house with these equipment configurations are not provided by the RESNET procedures.

The percentage change in space-heating energy consumptions specified in the RESNET procedures are based on modeling results using six detailed hourly simulation programs: two DOE-2.1E tools, two DOE2.2 tools, Micropas version 6.5, and TRNSYS version 15. Thus, it should be stressed for this analysis, as it was stressed for the space-heating load analysis, that the accuracy of MHEA's space-heating energy consumption calculations is being assessed based on a comparison with calculations made by other simulation programs rather than to measurements of actual consumptions in real houses.

As was done for the space-heating load calculations, these analyses were performed using the climate data for Colorado Springs, Colorado, as required by the RESNET procedures. Also, MHEA's input for the base house was again modified so that the UA-values calculated by MHEA for each of the envelope components were equal to the UA-values specified by BESTEST. By performing the analysis in this way, the ability of MHEA to accurately translate a space-heating load into a space heating energy consumption for different types of space-heating equipment could be isolated from its ability to accurately calculate UA-values.

Initial results indicated that MHEA's calculations for heat pump systems were incorrect. Further analysis revealed that MHEA was not using modified HSPFs for heat pumps that take into account the dependence of HSPF ratings on climate. After MHEA was modified using equations proposed by Fairey et al. (2004) to account for climate impacts on HSPF, MHEA was found to accurately calculate the changes in spaceheating energy consumptions specified by the RESNET procedures (see Table 3.1). Therefore, the conclusion reached from this analysis is that the corrected MHEA accurately calculates space-heating energy consumptions for the tested heating systems if the correct UA-values and other input are used such that the space-heating load is accurate. 
Table 3.1. Comparison of MHEA and RESNET space-heating energy consumptions

\begin{tabular}{|c|c|c|c|c|}
\hline \multirow{2}{*}{$\begin{array}{c}\text { Type of space- } \\
\text { heating system }\end{array}$} & \multirow{2}{*}{$\begin{array}{c}\text { Base space- } \\
\text { heating system }\end{array}$} & \multicolumn{3}{|c|}{ Change in space-heating energy consumption } \\
\cline { 3 - 4 } & \multicolumn{2}{|c|}{ RESNET acceptance criteria } & \multirow{2}{*}{ MHEA } \\
\cline { 3 - 4 } & Minimum & Maximum & $-13.3 \%$ \\
\hline $\begin{array}{c}90 \% \text { AFUE gas } \\
\text { furnace }\end{array}$ & $\begin{array}{c}78 \% \text { AFUE gas } \\
\text { furnace }\end{array}$ & $-11.6 \%$ & $-13.3 \%$ & $-18.3 \%$ \\
\hline $\begin{array}{c}9.85 \text { HSPF heat } \\
\text { pump }\end{array}$ & $\begin{array}{c}6.8 \text { HSPF heat } \\
\text { pump }\end{array}$ & $-16.7 \%$ & $-29.0 \%$ & $52.3 \%$ \\
\hline $\begin{array}{c}\text { Electric resistance } \\
\text { furnace }\end{array}$ & $\begin{array}{c}6.8 \text { HSPF heat } \\
\text { pump }\end{array}$ & $41.8 \%$ & $80.8 \%$ & \\
\hline
\end{tabular}




\section{ANALYSES TO TRUE-UP ENERGY ESTIMATES TO MEASURED VALUES}

The analyses presented in Sects. 2 and 3 showed that the corrected MHEA accurately calculates UAvalues, space-heating loads, and space-heating energy consumption based on a comparison with more detailed, hourly simulation programs. Thus, these analyses did not reveal why MHEA's estimates of space-heating energy savings did not agree with savings measured in the MHEA field validation or how to modify MHEA so that its energy savings estimates would agree with these measured values. In this section, the analyses performed and the modifications made to MHEA to true-up its space-heating energy savings estimates with the savings measured in the MHEA field validation homes are presented.

\subsection{ORIGINAL MHEA FIELD VALIDATION STUDY RESULTS}

Results from the original MHEA field validation study are shown in Table 4.1 for all the houses used in the study as well as a subset of 43 houses with higher quality data (i.e., the high-quality homes). The primary space-heating fuel used in the 86 field study homes was either natural gas (49 homes), propane (19 homes), or electricity (18 homes). The subset of homes with high-quality data was limited to those in which the regression analysis of the primary space-heating fuel passed selected reliability criteria and, for homes heated primarily by natural gas or propane, to those in which electric billing data had been collected so that any supplemental space-heating energy use could be determined. The high-quality data set was comprised of 23 homes heated primarily by natural gas, 6 homes heated primarily by propane, and 14 homes heated by electricity.

As shown in Table 4.1, the original field validation study found that MHEA over predicted the spaceheating energy savings by $186 \%$ and achieved a realization rate of $35 \%$ in the subset of 43 homes with high-quality data and considering supplemental electric space-heating. MHEA's performance was about the same whether all the houses were considered or just the subset with high-quality data, and whether supplemental electric space-heating was considered. Therefore, in the remainder of Sect. 4, results will only be discussed for the high-quality data set and including supplemental electricity use because their results are considered the most accurate and are representative of the other two groups.

Fig. 4.1 shows how the version of MHEA used in the field validation study over predicted the preweatherization space-heating energy consumption of a majority of the mobile homes, while Fig. 4.2 shows how MHEA's prediction of post-weatherization consumptions were much more accurate (from Table 4.1, the pre-weatherization space-heating energy consumption was over predicted by an average of $33 \%$, and the post-weatherization consumption was under predicted by an average of $7 \%$ ). In fact, MHEA over predicted the pre-weatherization space-heating energy consumption by more than $30 \%$ in 23 of the 43 houses with high-quality data (53\% of the homes) while under predicting the consumption by more than $30 \%$ in just 2 homes (5\%). MHEA's estimates of post-weatherization space-heating energy consumptions in the individual homes were more evenly distributed above and below the line of equivalence. In Fig. 4.3, MHEA's over prediction of energy savings is evident, as MHEA over predicted the space-heating energy savings by more than $50 \%$ in 26 homes $(60 \%)$.

\subsection{RESULTS FOLLOWING UA-CALCULATION MODIFICATIONS}

Since some minor modifications had been made to the R-values assumed in MHEA and in the algorithms used to calculate component UA-values as part of the UA analysis (see Sect. 2.1), a modified version of MHEA with these changes was re-applied to the houses used in the MHEA field validation to determine their impact on MHEA's overall performance. Table 4.1 shows that the impact of the changes made in MHEA's R-value assumptions and UA calculations on its overall performance was small: MHEA's over prediction of space-heating energy savings was still $163 \%$ and the realization rate was $38 \%$. 
Table 4.1. Impacts of MHEA modifications on its overall predictive performance

\begin{tabular}{|c|c|c|c|c|c|c|c|c|}
\hline \multirow[b]{3}{*}{ Houses } & \multicolumn{4}{|c|}{ Without supplemental electricity use* } & \multicolumn{4}{|c|}{ With supplemental electricity use* } \\
\hline & \multicolumn{3}{|c|}{ MHEA over-prediction } & \multirow{2}{*}{$\begin{array}{l}\text { Realization } \\
\text { rate }\end{array}$} & \multicolumn{3}{|c|}{ MHEA over-prediction } & \multirow{2}{*}{$\begin{array}{l}\text { Realization } \\
\text { rate }\end{array}$} \\
\hline & Pre & Post & Savings & & Pre & Post & Savings & \\
\hline \multicolumn{9}{|c|}{ Original MHEA Field Validation Study: } \\
\hline $\begin{array}{l}\text { All houses ( } 86 \\
\text { pre, } 72 \text { post) }\end{array}$ & $33 \%$ & $-2 \%$ & $196 \%$ & $34 \%$ & & & & \\
\hline $\begin{array}{l}\text { High-quality } \\
\text { houses (43) }\end{array}$ & $44 \%$ & $2 \%$ & $191 \%$ & $34 \%$ & $33 \%$ & $-7 \%$ & $186 \%$ & $35 \%$ \\
\hline \multicolumn{9}{|c|}{ After UA-Calculation Modifications: } \\
\hline $\begin{array}{l}\text { High-quality } \\
\text { houses (43) }\end{array}$ & $35 \%$ & $-3 \%$ & $168 \%$ & $37 \%$ & $24 \%$ & $-12 \%$ & $163 \%$ & $38 \%$ \\
\hline \multicolumn{9}{|c|}{ Following Engineering Modifications and Modeling Changes: } \\
\hline $\begin{array}{l}\text { High-quality } \\
\text { houses (43) }\end{array}$ & $16 \%$ & $-12 \%$ & $113 \%$ & $47 \%$ & $6 \%$ & $-20 \%$ & $109 \%$ & $48 \%$ \\
\hline $\begin{array}{l}\text { High-quality } \\
\text { houses and } \\
\text { eliminating } \\
\text { "zero" energy } \\
\text { savers (35) }\end{array}$ & & & $66 \%$ & $60 \%$ & & & $61 \%$ & $62 \%$ \\
\hline \multicolumn{9}{|c|}{ After 0.6 Correction Factor Applied to Energy Savings: } \\
\hline $\begin{array}{l}\text { High-quality } \\
\text { houses (43) }\end{array}$ & $16 \%$ & $12 \%$ & $28 \%$ & $79 \%$ & $6 \%$ & $1 \%$ & $25 \%$ & $80 \%$ \\
\hline \multicolumn{9}{|c|}{ Using MHEA's Billing Adjustment Feature: } \\
\hline $\begin{array}{l}\text { High-quality } \\
\text { houses (43) }\end{array}$ & $16 \%$ & $15 \%$ & $16 \%$ & $87 \%$ & $6 \%$ & $4 \%$ & $14 \%$ & $88 \%$ \\
\hline
\end{tabular}

*Supplemental space-heating electricity use was determined for homes heated primarily by natural gas or propane from a PRISM analysis of the electric billing data. For homes in which natural gas or propane was the primary space-heating fuel, the actual space-heating energy consumption was calculated in two ways: (a) based only on the primary space-heating fuel consumption (i.e., on the natural gas or propane consumption without including the supplemental electricity use); and (b) by adding the supplemental space-heating electricity use to the natural gas or propane space-heating consumption. 


\section{Pre-Weatherization \\ (Original MHEA Field Validation Study)}

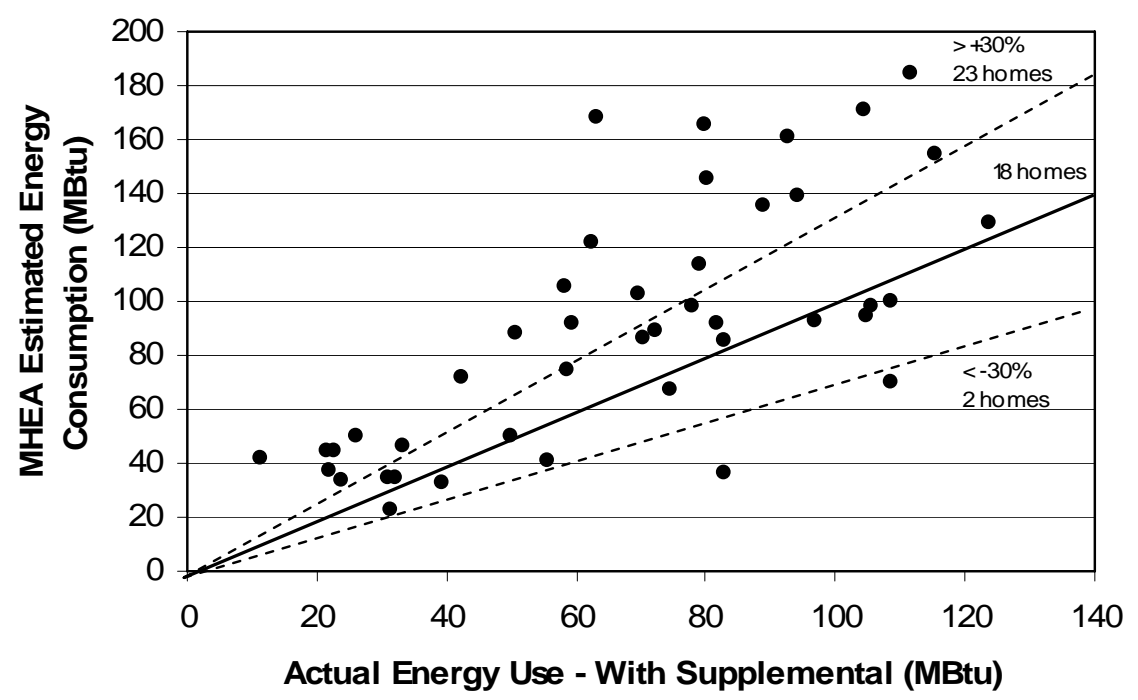

Fig. 4.1. Comparison of MHEA's estimate of the pre-weatherization annual energy consumption to the actual measured energy consumption in each of the $\mathbf{4 3}$ mobile homes with high-quality data as determined in the original MHEA field validation study. The solid line shows equivalency between actual and estimated energy use, and the dashed lines show deviations in estimated consumption from actual by $+/-30 \%$.

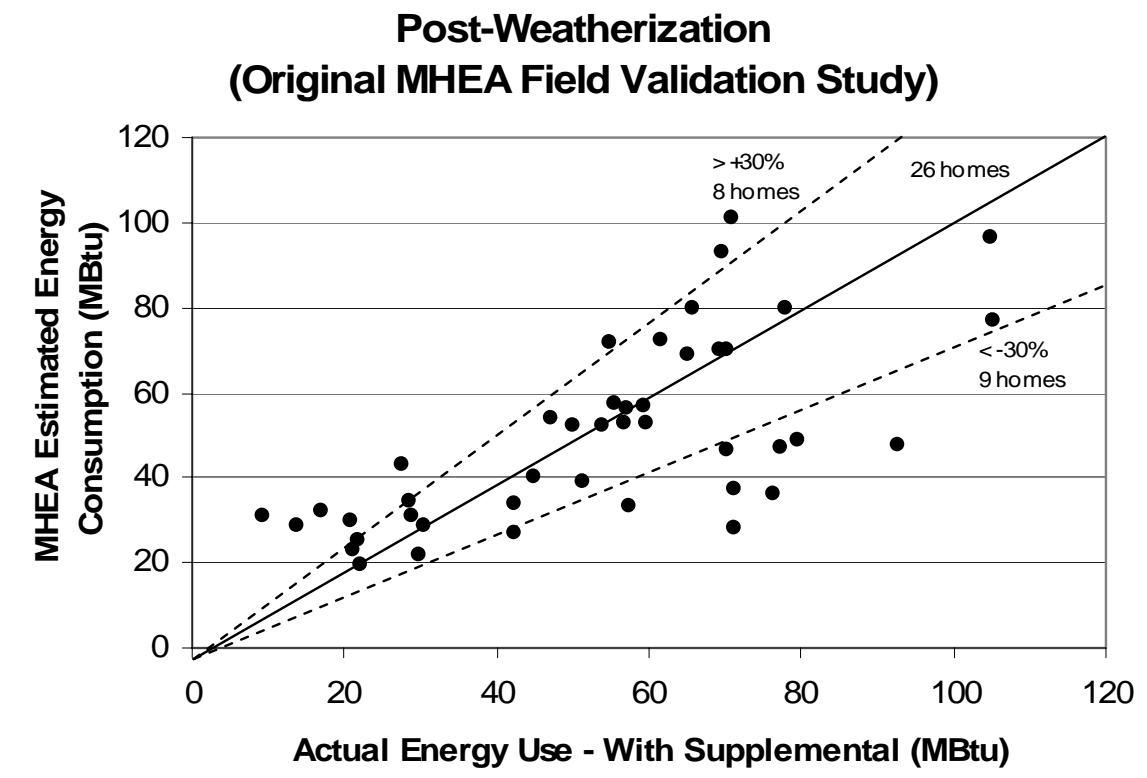

Fig. 4.2. Comparison of MHEA's estimate of the post-weatherization annual energy consumption to the actual measured energy consumption in each of the $\mathbf{4 3}$ mobile homes with high-quality data as determined in the original MHEA field validation study. The solid line shows equivalency between actual and estimated energy use, and the dashed lines show deviations in estimated consumption from actual by $+/-30 \%$. 


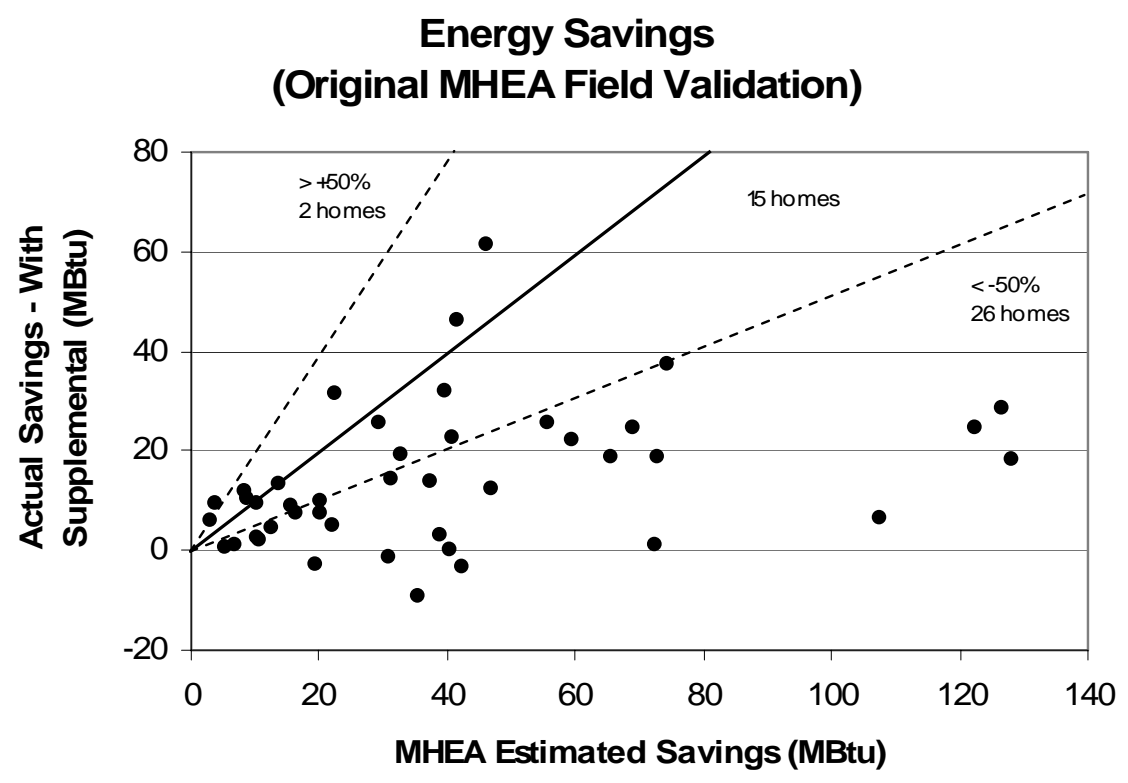

Fig. 4.3. Comparison of MHEA's estimated annual energy savings to the actual measured energy savings in each of the 43 mobile homes with high-quality data as determined in the original MHEA field validation study. The solid line shows equivalency between actual and estimated energy savings, and the dashed lines show deviations in estimated savings from actual by $+/-50 \%$.

\subsection{ENGINEERING MODIFICATIONS AND MODELING CHANGES}

Even though MHEA was shown to be accurate when compared with other simulation programs, the next step was to identify reasonable, engineering-based modifications that could be made to MHEA to true-up MHEA's energy savings estimates with measured values. The results for individual mobile homes used in the MHEA field validation were examined to try to determine the cause of MHEA's over prediction of space-heating energy savings. This analysis included trying to determine common characteristics of mobile homes in which MHEA was not accurately estimating pre-weatherization space-heating energy consumption, post-weatherization energy consumption, and/or space-heating energy savings. Special emphasis was placed on reducing MHEA's over prediction of pre-weatherization space-heating energy consumption, which originally averaged $33 \%$ (see Table 4.1). In the end, three modifications to MHEA were identified as necessary to improve MHEA's accuracy:

1. The internal loads assumed in MHEA for appliances and two adult occupants were changed from $2400 \mathrm{Btu} / \mathrm{h}$ during the day and $1000 \mathrm{Btu} / \mathrm{h}$ at night to $1950 \mathrm{Btu} / \mathrm{h}$ and $2350 \mathrm{Btu} / \mathrm{h}$, respectively. ${ }^{3}$ With these changes, MHEA's average internal load value of $2150 \mathrm{Btu} / \mathrm{h}$ is consistent with the HERS standard reference house assuming three bedrooms and a floor area of $900 \mathrm{ft}^{2}$, which is the average floor area of the 86 homes monitored as part of the MHEA field validation study. This average internal load is also just slightly less than the $2600 \mathrm{Btu} / \mathrm{h}$ that will be used in future versions of NEAT for site-built homes (the current value is $2900 \mathrm{Btu} / \mathrm{h}$ ), which tend to have slightly more floor area than mobile homes. The higher value at night compared with the day is based on the internal load profile used by BESTEST. It should be noted that this change would have no effect on the analyses presented in Sects. 2 and 3 because internal loads specified by BESTEST were used in these analyses.

\footnotetext{
${ }^{3}$ The internal loads are actually input fields in MHEA's setup library. However, they are rarely changed by users, so the values provided at the time MHEA is distributed are essentially default values. If the number of occupants entered by the user is less than or more than 2, then MHEA adjusts the internal loads based on the actual occupancy.
} 
2. The load MHEA calculates for infiltration from blower door readings was reduced by about $25 \%$. The UA-values MHEA effectively calculated for infiltration and infiltration loads being calculated by MHEA were already less than BESTEST. However, examination of the results for the 43 houses with high-quality data showed that infiltration was still contributing to over prediction problems: MHEA over predicted the pre-weatherization space-heating energy consumption of 4 of 6 homes with infiltration rates greater than $4000 \mathrm{cfm} 50$ by more than $30 \%$, and MHEA under predicted the postweatherization energy consumption of 2 of 4 homes with air leakage reductions of more than 2300 cfm50. In addition, examination of the space-heating savings estimated by MHEA for infiltration reduction appeared to be abnormally high on an absolute magnitude basis and as a percentage of the estimated pre-weatherization space-heating energy consumption. For example:

- For a house with a MHEA-estimated pre-weatherization space-heating energy consumption of 43.3 MBtu, MHEA was estimating a savings of 8.1 MBTU, or 19\%, from a reduction in the infiltration rate from $2635 \mathrm{cfm} 50$ to $1580 \mathrm{cfm} 50$. The modification to MHEA's infiltration load calculation reduced this savings to a more modest $15 \%$.

- For a house with a MHEA-estimated pre-weatherization space-heating energy consumption of 155.7 MBtu, MHEA was estimating a savings of $59.0 \mathrm{MBTU}$, or $38 \%$, from a reduction in the infiltration rate from $4942 \mathrm{cfm} 50$ to $1656 \mathrm{cfm} 50$. The modification to MHEA's infiltration load calculation reduced MHEA's pre-weatherization space-heating energy consumption estimate to 144.1 MBtu and the savings to 44.2 MBtu (31\%).

3. An R-value of 1 was added to the ceiling, floor, and walls in calculating the UA-value of these envelope components. ${ }^{4}$ In mobile homes, the effective insulation level of floors, walls, and to a lesser extent ceilings is possibly higher than that based on engineering calculations that only considered the structure of the mobile home, especially when little or no insulation is installed in these envelope areas. For example, closets and cabinets which can represent a high percentage of the wall, ceiling, and floor area in a mobile home may be acting as buffer spaces that increase the effective R-value of these envelope areas. Likewise, furniture in the homes (especially furniture placed against the exterior wall like couches and dressers) may also be increasing the effective R-value of the floor and walls. Several analyses supported these beliefs:

- On average, MHEA over predicted the pre-weatherization space-heating energy consumption of the mobile homes when insulation levels were generally low, but more accurately predicted the post-weatherization consumption when insulation levels were higher.

- A common characteristic found in a subgroup of homes in which MHEA over predicted preweatherization space-heating energy consumption by $30 \%$ or more was that many of their envelope components had little to no insulation in them. This characteristic was not as evident in the homes in which MHEA more accurately predicted pre-weatherization energy consumption.

In addition to the three modifications made in MHEA described above, two other changes were made to how some of the 43 homes with high-quality data were modeled in MHEA before MHEA-estimated energy consumptions and savings were re-compared with measured values. This was done to ensure that the selection of modifications to MHEA to true-up predicted space-heating savings to measured values and the success or failure of these modifications would not be based on inadequate weatherization measures or inaccurate input data. These two changes are described below:

\footnotetext{
${ }^{4}$ The addition of an R-value of 2 rather than 1 was also examined but not used because little additional improvement was observed.
} 
1. A programmable (i.e., setback) thermostat was installed in 5 of the 43 homes, but MHEA was configured in each of these 5 houses to predict no space-heating energy savings from this measure. Unlike other weatherization measures installed in these five homes, it was unknown how frequently the setback feature was used and if used at all, what degree of setback occurred. Examination of the initial results for these five homes showed that MHEA was under predicting the post-weatherization space-heating energy consumption of three of them. Previous modifications to MHEA that reduced the amount of setback assumed in MHEA from $5^{\circ} \mathrm{F}$ to $3^{\circ} \mathrm{F}$ had reduced the annual savings associated with setback thermostats to about 3-5 MBtu, so ignoring the possible savings from this measure only slightly affected the final post-weatherization energy consumptions and savings predicted by MHEA.

2. In 6 of the 43 homes, the amount of floor insulation was initially entered as zero. The floors of these 6 homes (which were limited to 2 agencies) were the only envelope areas in the 43 homes with no insulation. The amount of floor insulation in these 6 homes was increased from 0 to $0.5 \mathrm{in}$. because: (a) most mobile homes were initially built with floor insulation, and (b) it was believed that these two agencies were entering zero for the amount of existing floor insulation to describe floors in which the insulation and belly wrap had become significantly destroyed and/or were in very poor condition, even though it was likely that some insulation remained.

As shown in Table 4.1, the overall impact of the MHEA modifications and modeling changes described above was to reduce the over prediction of space-heating energy savings from $163 \%$ to $109 \%$ and increase the realization rate from $38 \%$ to $48 \%$. A more detailed discussion of the impacts of these modifications and changes are described below:

- $\quad$ MHEA's over prediction of pre-weatherization space-heating energy consumption was reduced from $33 \%$ to $6 \%$. This improved accuracy can be seen by comparing Fig. 4.4 with Fig. 4.1. Following the modifications and changes, MHEA's prediction of pre-weatherization space-heating energy consumption was within $\pm 30 \%$ for most homes, with equal distribution of homes around the line of equivalency. The homes that were impacted the most were the homes with the greatest difference between predicted and actual consumption before the modifications and changes were made.

- Unfortunately, the modifications and changes adversely affected MHEA's post-weatherization spaceheating energy consumption estimates. MHEA's under prediction of post-weatherization spaceheating energy consumption increased from $7 \%$ to $20 \%$. This change is evident by comparing Fig 4.5 with Fig. 4.2. Although the number of homes with predictions within $\pm 30 \%$ actually increased, most homes were below the line of equivalency (indicating an under prediction of energy consumption).

- The net result from the changes in pre- and post-weatherization energy consumption predictions was an improvement in the prediction of space-heating energy savings for most homes. As a comparison of Fig. 4.6 with Fig. 4.3 shows, there is a greater number of homes with energy savings predictions within $\pm 50 \%$ of actual and a better concentration of homes near the line of equivalency. The greatest improvement in space-heating energy savings predictions generally occurred in those homes that were the furthest off before (e.g., see the improvement in the four homes in Fig. 4.3 in which MHEA originally predicted an annual energy savings of more than $100 \mathrm{MBtu}$ ).

The conclusions reached regarding the modifications made to MHEA and the changes in how some of the houses were modeled in MHEA were that they were valid and in the right direction. Pre-weatherization space-heating energy consumption predictions and energy savings estimates were greatly improved despite the decreased accuracy in post-weatherization space-heating energy consumption predictions. Improvements were seen especially in homes with little or no insulation and/or high infiltration before weatherization, and in homes whose estimates of pre-weatherization energy consumption and/or energy 


\section{Pre-Weatherization}

(After Final Modifications)

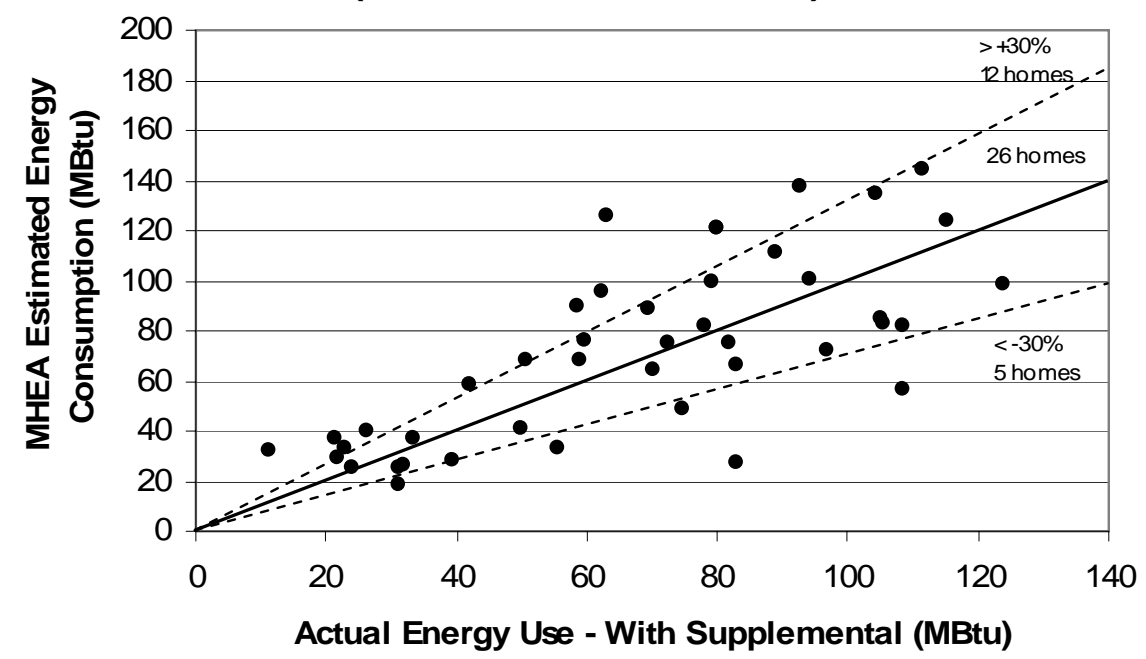

Fig. 4.4. Comparison of MHEA's estimate of the pre-weatherization annual energy consumption to the actual measured energy consumption in each of the 43 mobile homes with high-quality data after modifications were made to MHEA and changes were made in how some of the homes were modeled in MHEA. The solid line shows equivalency between actual and estimated energy use, and the dashed lines show deviations in estimated consumption from actual by $+/-30 \%$.

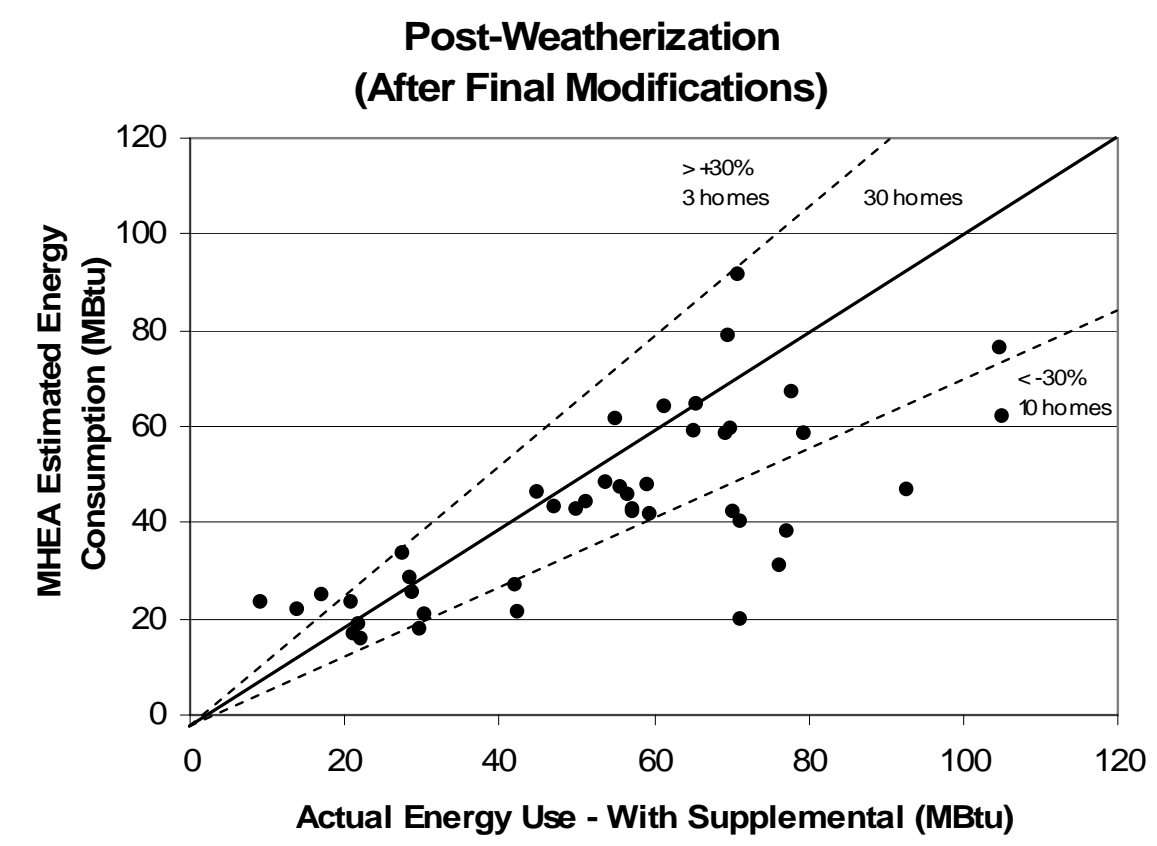

Fig. 4.5. Comparison of MHEA's estimate of the post-weatherization annual energy consumption to the actual measured energy consumption in each of the 43 mobile homes with high-quality data after modifications were made to MHEA and changes were made in how some of the homes were modeled in MHEA. The solid line shows equivalency between actual and estimated energy use, and the dashed lines show deviations in estimated consumption from actual by $+/-30 \%$. 


\section{Energy Savings (After Final Modifications)}

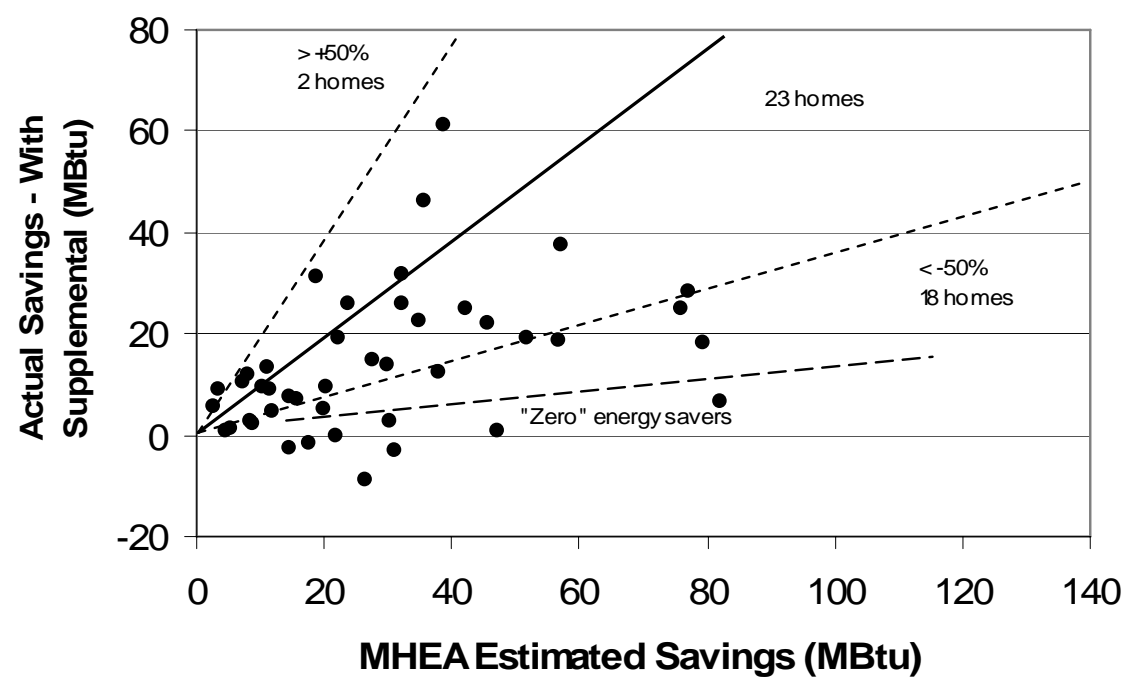

Fig. 4.6. Comparison of MHEA's estimated annual energy savings to the actual measured energy savings in each of the $\mathbf{4 3}$ mobile homes with high-quality data after modifications were made to MHEA and changes were made in how some of the homes were modeled in MHEA. The solid line shows equivalency between actual and estimated energy savings, and the dashed lines show deviations in estimated savings from actual by $+/-50 \%$.

savings deviated the most from actual values before the modifications and changes were made. However, it was also evident that these modifications and changes were not sufficient to completely true-up MHEA's predicted savings to measured values.

\subsection{CORRECTION FACTOR}

Since no further valid engineering-based modifications could be identified to finish truing-up MHEA's predicted savings to measured values, MHEA was modified by multiplying the space-heating energy savings of all measures by a 0.6 correction factor (i.e., reducing the energy savings by $40 \%$ ) to complete the truing-up process. MHEA's realization rate of about 50\% following the implementation of the MHEA modifications and modeling changes would have indicated the need for a 0.5 correction factor. However, a 0.6 correction factor was chosen instead after excluding homes with "zero" energy savings so that the correction factor would be based just on homes that were "well behaved." As shown in Fig. 4.6, 8 of the 43 homes with high-quality data were identified as "zero" energy savers. In these homes, either the actual measured space-heating energy consumption stayed the same or increased following weatherization (zero or negative energy savings) or the actual measured space-heating energy savings was nearly zero despite the installation of weatherization measures that were expected to save 40 or even 80 MBtu per year. ${ }^{5}$ The realization rate calculated for just the 35 "well behaved" homes was $62 \%$, indicating the need for a 0.6 correction factor to true-up their average estimated savings to measured values. A 0.6 correction factor was chosen instead of a 0.5 correction factor so the somewhat arbitrary reduction in MHEA's estimated space-heating savings would not be based on homes that were not well understood.

\footnotetext{
${ }^{5}$ Inclusion of the home with an actual annual energy savings of about 3-5 MBtu and a MHEA estimated savings of about 30 MBtu as a "zero" energy saver is debatable.
} 
By incorporating this 0.6 correction factor into MHEA's space-heating energy savings calculations, MHEA's post-weatherization space-heating energy consumptions were improved to be within $1 \%$ of actual, the over prediction of space-heating energy savings was reduced from $109 \%$ to just $25 \%$, and the realization rate was increased from $48 \%$ to $80 \%$ (the correction factor had no effect on MHEA's preweatherization space-heating energy consumption predictions, which remained within $6 \%$ of actual). These results are shown in Table 4.1. The better distribution of homes around the line of equivalency when considering post-weatherization space-heating energy consumption is evident from comparing Fig. 4.7 with Fig. 4.5. The reduction in MHEA's space-heating energy saving estimates (the shift of the homes to the left) and the better clustering of homes around the line of equivalency are evident in comparing Fig. 4.8 with Fig. 4.6. Note that the 0.6 correction factor had little effect on improving the performance of MHEA in the "zero" energy homes.

\subsection{USE OF MHEA'S OPTIONAL BILLING ADJUSTMENT FEATURE}

MHEA includes an optional billing adjustment feature that adjusts its annual energy savings estimates of measures based on pre-weatherization billing data (if entered). MHEA analyzes these data to determine actual annual space-heating energy consumption and compares this to its annual pre-weatherization space-heating energy consumption estimate, which is based on the characteristics of the mobile home. MHEA decreases its estimated annual space-heating energy savings for all heating-related weatherization measures if the annual space-heating energy consumption indicated by the billing data is less than MHEA's estimate, and increases its estimated annual space-heating energy savings if the reverse is true. The change is approximately proportional to the ratio between the annual pre-weatherization spaceheating energy consumption based on the billing data to that estimated by MHEA. For example, if MHEA estimated an annual pre-weatherization space-heating energy consumption of $100 \mathrm{MBtu}$ and the billing data indicated an annual consumption of $80 \mathrm{MBtu}$, then the ratio is $80 / 100$ or 0.8 , and MHEA would decrease the annual space-heating energy savings of all heating-related measures to about $80 \%$ of their original values (or by about $20 \%$ ).

The use of MHEA's billing adjustment feature was analyzed in the original MHEA field validation study. Use of the adjustment feature reduced the over prediction of space-heating energy savings by over 50\% (from $186 \%$ to $88 \%$ ) and increased the realization rate from $35 \%$ to $53 \%$. Thus, the billing adjustment feature alone was unable to fully correct MHEA's predictions.

Now that MHEA's performance had been drastically improved through the implementation of the engineering modifications and a correction factor as described in Sects 4.3 and 4.4, the benefit of using MHEA's billing adjustment feature was again analyzed. As shown in Table 4.1, use of the billing adjustment feature along with all the other changes previously described reduced MHEA's over prediction of space-heating energy savings from $25 \%$ to just $14 \%$ and increased its realization rate from $80 \%$ to $88 \%$.

The engineering modifications and correction factor affected all the homes in the same way (i.e., they reduced MHEA's space-heating energy savings predictions in all houses, even those in which MHEA was under predicting the energy savings). However, use of the billing adjustment feature tended to reduce MHEA's space-heating energy savings prediction in homes in which the savings was being over predicted and increase it in homes in which those savings were being under predicted. As a result, the billing adjustment not only improved MHEA's overall performance, but also improved MHEA's performance in most individual homes. This is evident from comparing Fig. 4.9 with Fig. 4.8. Individual homes are grouped much more closely around the line of equivalency in Fig. 4.9 than in Fig. 4.8, and movement toward the line of equivalency occurred in homes with under predicted savings and those with over predicted savings. 


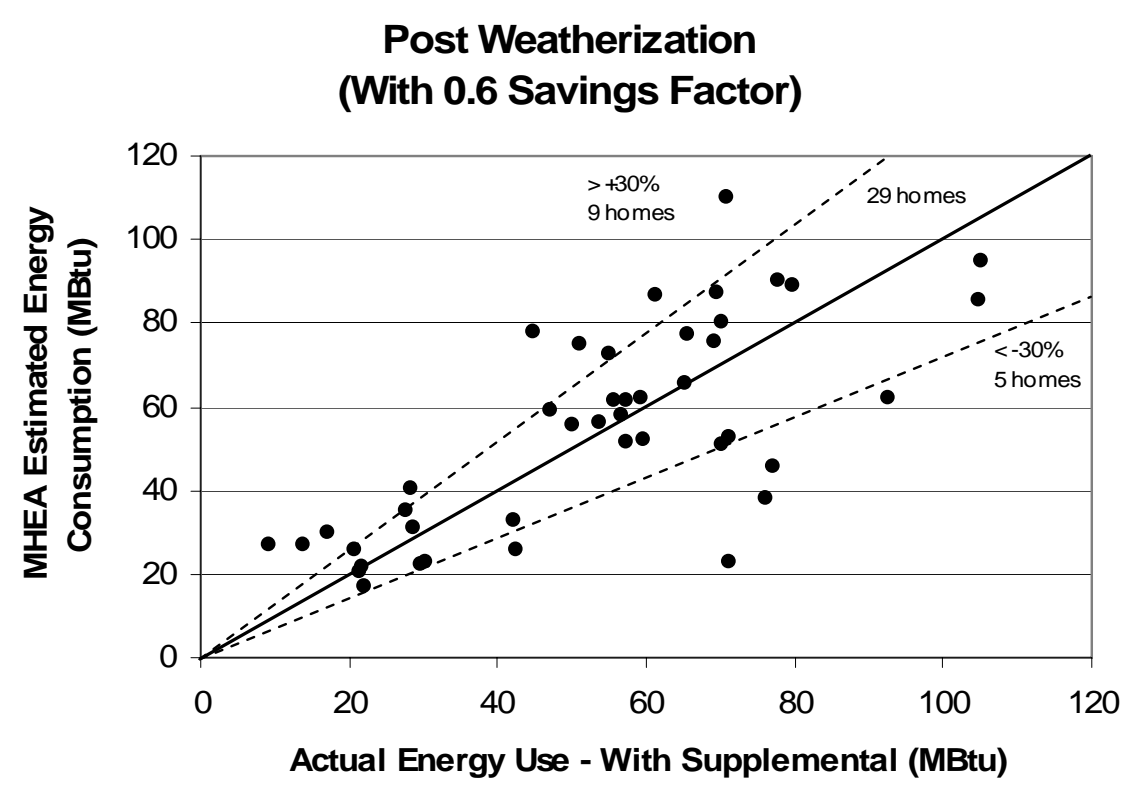

Fig. 4.7. Comparison of MHEA's estimate of the post-weatherization annual energy consumption to the actual measured energy consumption in each of the 43 mobile homes with high-quality data after modifications were made to MHEA, changes were made in how some of the homes were modeled in MHEA, and a 0.6 correction factor was applied to the energy saving calculations. The solid line shows equivalency between actual and estimated energy use, and the dashed lines show deviations in estimated consumption from actual by $+/-30 \%$.

\section{Energy Savings (With 0.6 Savings Factor)}

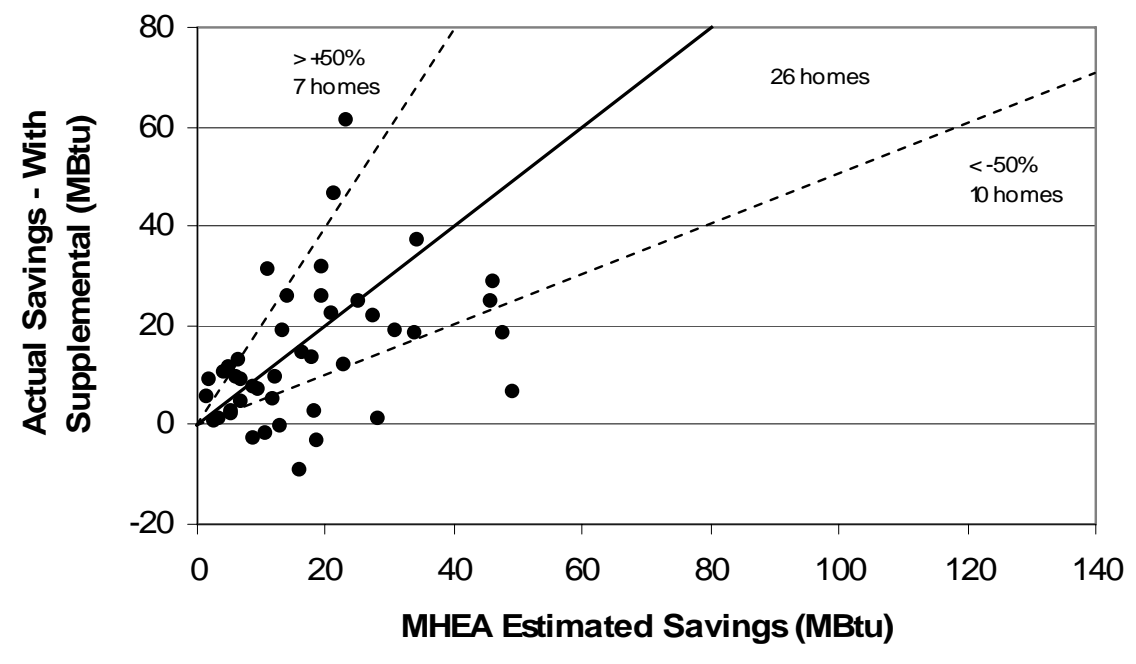

Fig. 4.8. Comparison of MHEA's estimated annual energy savings to the actual measured energy savings in each of the 43 mobile homes with high-quality data after modifications were made to MHEA, changes were made in how some of the homes were modeled in MHEA, and a 0.6 correction factor was applied to the energy saving calculations. The solid line shows equivalency between actual and estimated energy savings, and the dashed lines show deviations in estimated savings from actual by $+/-50 \%$. 


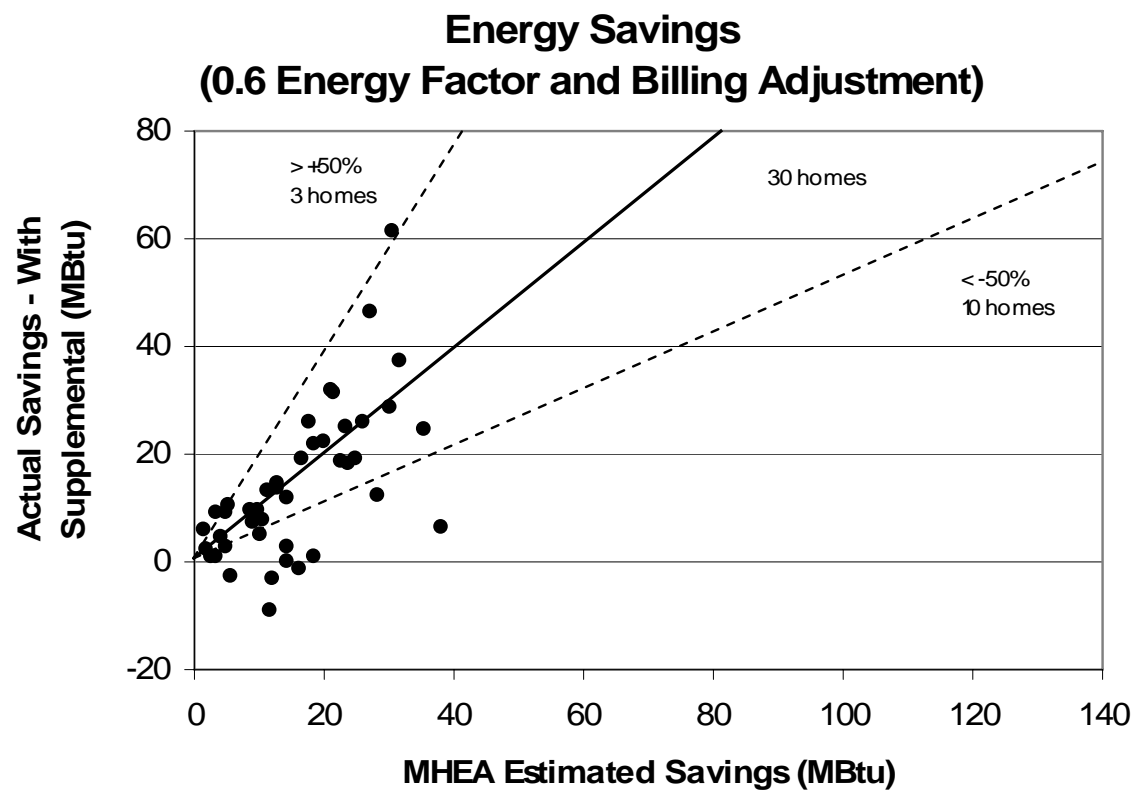

Fig. 4.9. Comparison of MHEA's estimated annual energy savings to the actual measured energy savings in each of the 43 mobile homes with high-quality data after modifications were made to MHEA, changes were made in how some of the homes were modeled in MHEA, a 0.6 correction factor was applied to the energy saving calculations, and MHEA's billing adjustment feature was utilized. The solid line shows equivalency between actual and estimated energy savings, and the dashed lines show deviations in estimated savings from actual by $+/-50 \%$. 


\section{PROGRAM IMPACTS FROM USE OF A REVISED MHEA}

Although the revisions made to MHEA as described in Sect. 4 were shown to improve the accuracy of MHEA as compared with field data, questions remained on how the changes outlined in Sects. 4.3 and 4.4 (principally the 25\% infiltration load reduction; adding an R-value of 1 to the ceiling, walls, and floor; and use of a 0.6 correction factor) might impact a weatherization program. The two primary questions dealt with the change in frequency that measures might be recommended and the change in total investment that might occur. Because predicted energy savings are less in the revised version of MHEA, the concern was that the revised version would determine that most measures are no longer cost effective and, thus, few measures and little investment would be recommended in mobile homes.

Eighteen homes ( 13 heated by natural gas and 5 heated by electricity) used in the original MHEA field validation from Columbus, Ohio, were used in the analysis. Cost-effective measures as recommended using the revised version of MHEA (i.e., with all the major revisions outlined in Sects. 4.3 and 4.4 as well as the minor modifications made to the R-value assumptions and UA-algorithms outlined in Sect. 2.1) were identified for each home and compared with a version of MHEA that did not include the $25 \%$ infiltration load reduction, the added R-value of 1 , or the use of a 0.6 correction factor (to be referred to as the original version of MHEA). ${ }^{6}$ Current fuel costs and updated information needed by MHEA to estimate the cost of measures (e.g., material and labor costs to install insulation per bag of insulation and/or per job, material and labor costs to install storm windows per square foot of window area) were entered into both versions of the program. Because the homes had already been weatherized, health, safety, and repair items that had been performed on the homes were entered into MHEA as mandatory measures to simulate a real program.

Table 5.1 shows the results of this analysis. Key observations include:

- Although the revised version of MHEA recommended that ceiling and floor insulation be installed in fewer homes than the original MHEA (61\% instead of $72 \%$ for ceiling insulation, and $61 \%$ instead of $89 \%$ for floor insulation), it still recommended ceiling and floor insulation in more than half the homes. The homes in which insulation was no longer being recommended by the revised version of MHEA were those that already had a moderate amount of insulation; insulation was recommended by both versions of MHEA in homes with little or no insulation in the ceiling or floor.

- The recommendations concerning wall insulation did not change. Both versions of MHEA recommended wall insulation in those mobile homes that were identified as having none (i.e., in 3 of the 18 homes, or 17\%), although the savings-to-investment ratios (SIR) determined by the revised version of MHEA for these measures were approaching the cost-effective threshold of 1.0.

Fewer storm windows were recommended by the revised version of MHEA than the original version. The revised version of MHEA recommended the installation of at least one storm window in only $39 \%$ of the mobile homes compared with $83 \%$ by the original version of MHEA. More telling, the revised version of MHEA decreased the total number of storm windows recommended for these 18 homes as evidenced by the reduction in average cost ( $\$ 82$ compared with $\$ 546$ ). Because of the costing structure used in MHEA to estimate the cost of the storm windows (cost per square foot for labor and materials), the revised version of MHEA was determining that a storm window installed on a small window (e.g., a $2 \mathrm{ft} \times 2 \mathrm{ft}$ bathroom window) was often just cost effective (i.e., the SIR was

\footnotetext{
${ }^{6}$ The revised version of MHEA was compared with a version of MHEA that included changes in the R-value assumptions, improvements in the UA-algorithms, and updated internal loads because these changes were determined necessary regardless of the other revisions being studied.
} 
just greater than 1.0). If a different costing structure available in MHEA had been used (cost per square foot for material but a set labor cost for the installation of the window), the revised version of MHEA would likely have recommended even fewer storm windows.

Table 5.1. Summary of recommendations for the 18 Ohio mobile homes

\begin{tabular}{|l|c|c|c|c|}
\hline \multirow{2}{*}{\begin{tabular}{l} 
Measure \\
\cline { 2 - 5 }
\end{tabular}} & $\begin{array}{c}\text { Original version of MHEA } \\
\text { Frequency } \\
\text { recommended }\end{array}$ & $\begin{array}{c}\text { Average estimated cost } \\
\text { per all 18 homes } \\
\text { (\$) }\end{array}$ & $\begin{array}{c}\text { Revised version of MHEA } \\
\text { Frequency } \\
\text { recommended }\end{array}$ & $\begin{array}{c}\text { Average estimated cost } \\
\text { per all 18 homes } \\
\text { (\$) }\end{array}$ \\
\hline $\begin{array}{l}\text { Mobile home ceiling } \\
\text { insulation }\end{array}$ & $72 \%$ & $\$ 637$ & $61 \%$ & $\$ 542$ \\
\hline $\begin{array}{l}\text { Mobile home wall } \\
\text { insulation }\end{array}$ & $17 \%$ & $\$ 72$ & $17 \%$ & $\$ 72$ \\
\hline $\begin{array}{l}\text { Mobile home floor } \\
\text { insulation }\end{array}$ & $89 \%$ & $\$ 598$ & $61 \%$ & $\$ 439$ \\
\hline $\begin{array}{l}\text { Storm windows } \\
\text { New space-heating } \\
\text { system }\end{array}$ & $11 \%$ & $\$ 552$ & $39 \%$ & $\$ 85$ \\
\hline $\begin{array}{l}\text { Infiltration and duct } \\
\text { sealing }\end{array}$ & $100 \%$ & $\$ 124$ & $6 \%$ & $\$ 63$ \\
\hline $\begin{array}{l}\text { Other energy } \\
\text { measures } 1\end{array}$ & $\$ 191$ & $\$ 100 \%$ & $\$ 191$ \\
\hline $\begin{array}{l}\text { Health, safety, and } \\
\text { repair items }\end{array}$ & & $\$ 62$ & & $\$ 58$ \\
\hline Total & $\$ 2838$ & & $\$ 2194$ \\
\hline
\end{tabular}

${ }^{1}$ Other energy measures include ceiling, wall, or floor insulation in a mobile home addition; space-heating system tune-up; and water heater or pipe insulation.

${ }^{2}$ These items include new water heaters installed in four homes, new doors installed in four homes, new spaceheating systems installed in two homes, work performed on the space-heating systems in three homes, and a new thermostat installed in one home. For the revised MHEA, they also include items that were needed but were no longer cost justified as in the original version of MHEA: a new space-heating system installed in a third home and storm windows installed in two homes.

- Although the installation of new, higher-efficiency space-heating systems was determined to be cost effective in two homes by the original version of MHEA, the revised version of MHEA determined that a new system was cost effective in just one of these homes.

- Although the average investment level decreased from $\$ 2838$ per home to $\$ 2194$ from use of the revised version of MHEA, it remained high. In fact, use of the revised version of MHEA changed the recommended investment level less than $\$ 130$ in 39\% of the homes.

The primary conclusion reached from this analysis is that use of the revised version of MHEA in a weatherization program would not automatically result in the wholesale elimination of cost-effective weatherization measure recommendations in mobile homes. Fewer storm windows would be recommended (a change that many experienced personnel in the weatherization community might agree with), but recommendations for ceiling, wall, and floor insulation would still be prevalent (especially as weatherization agencies learn how to reduce the installation costs). Although average investment levels per home may drop some, this investment drop may eliminate the installation of measures that are not cost effective and free-up funds to allow cost-effective measures to be installed in more homes. 


\section{CONCLUSIONS AND RECOMMENDATIONS}

A series of analyses were performed to investigate why MHEA significantly over predicted the spaceheating energy savings of weatherization measures installed in mobile homes as measured in a recently completed field validation study. In these analyses, the results of different MHEA calculations were compared with results calculated by other, more detailed computer models, which resulted in several small changes being made to MHEA. The primary conclusion reached from these analyses is that MHEA's basic energy algorithms are sound from an engineering perspective and, thus, are not the source of the energy-savings over prediction measured in the field test. Several specific conclusions are that:

- MHEA appropriately reflects mobile home construction and accurately calculates the UA-values of mobile home envelope components.

- MHEA's variable-based degree-day load calculation method accurately calculates space-heating energy loads if the correct UA-values and other input are used.

- $\quad$ MHEA accurately calculates the space-heating energy consumption for gas furnaces, heat pumps, and electric-resistance furnaces if the space-heating load and other input are accurate.

Even though MHEA's calculations were shown to be correct from an engineering point of view, modifications to MHEA's algorithms were developed to true-up MHEA's predicted savings to savings measured in the houses used in the recent MHEA field validation. It was concluded that the following four modifications (the first three of which are justifiable from an engineering perspective) would be needed to reduce MHEA's over prediction of energy savings from 186\% as measured in the field validation to an acceptable value of $25 \%$ (or $14 \%$ if MHEA's optional billing adjustment feature is used):

- Change the internal loads assumed in MHEA for appliances and two adult occupants from $2400 \mathrm{Btu} / \mathrm{h}$ during the day and $1000 \mathrm{Btu} / \mathrm{h}$ at night to $1950 \mathrm{Btu} / \mathrm{h}$ and $2350 \mathrm{Btu} / \mathrm{h}$, respectively, which makes MHEA's average internal load value of $2150 \mathrm{Btu} / \mathrm{h}$ consistent with the HERS standard reference house.

- Reduce the load MHEA calculates for infiltration from blower door readings by about $25 \%$ even though the UA-value MHEA effectively calculates for infiltration and the infiltration load being calculated by MHEA are already less than those calculated by other computer models.

- Add an R-value of 1 to the ceiling, floor, and walls when calculating the UA-value of these envelope components to address the idea that their effective insulation levels might be higher than those based on engineering calculations that only considered the structure of the mobile home (e.g., that do not take into account the insulation effect of closets, cabinets, and furniture resting on the floor or placed against an exterior wall, which can be prevalent in mobile homes).

- Multiply the space-heating energy savings predicted by MHEA for all measures by a 0.6 correction factor (i.e., reduce the predicted energy savings by $40 \%$ ).

An analysis was performed to study the impact these changes to MHEA might have on a weatherization program. The primary conclusion reached from this analysis is that a revised version of MHEA would still recommend a significant number of cost-effective weatherization measures in mobile homes (including ceiling, floor, and even wall insulation and far fewer storm windows). Although average investment levels per home may drop, this investment drop may eliminate the installation of measures 
that are not cost effective and free-up funds to allow cost-effective measures to be installed in a larger number of homes.

Based on these findings and conclusions, a revised version of MHEA with all the changes and modifications outlined in this report should be finalized and made available to the weatherization community as soon as possible, preferably in time for use within the 2009 Program Year. Even though the exact source of the original over prediction of energy savings remains unresolved, this revised version of MHEA is more accurate as compared with measured field data and improves the validity of its recommendations. The revised version of MHEA should be readily acceptable by states, and improved weatherization of mobile homes within the Weatherization Assistance Program should result from its use.

The analyses presented in this report focused only on space-heating. As a minimum, the accuracy of MHEA's space-cooling energy load and consumption predictions should be analyzed using the same HERS BESTEST and RESNET procedures used for space-heating. To further verify the accuracy of MHEA's space-cooling predictions, a field test should be performed so that predicted space-cooling energy consumptions and savings can be compared with measured values. 


\section{REFERENCES}

ASHRAE. 2001. Handbook of Fundamentals. American Society of Heating, Refrigerating and AirConditioning Engineers, Inc. Atlanta, GA. [http://www.ashrae.org].

Fairey, Philip, Danny Parker, Bruce Wilcox, and Mathew Lombardi. 2005. Climate Impacts on Heating Seasonal Performance Factor (HSPF) and Seasonal Energy Efficiency Ratio (SEER) for Air Source Heat Pumps. FSEC-PF-413-04. Florida Solar Energy Center, Cocoa, FL or ASHRAE Transactions. American Society of Heating, Refrigerating and Air Conditioning Engineers, Inc., Atlanta, GA. June 2004. [http://www.fsec.ucf.edu/en/publications/html/FSEC-PF-413-04/index.htm].

Judkoff, R. and J. Neymark. 1995. Home Energy Rating System Building Energy Simulation Test (HERS BESTEST), Volume 2: Tier 1 and Tier 2 Tests Reference Results. NREL/TP-472-7332b. National Renewable Energy Laboratory, Golden, CO. November.

[http://www.nrel.gov/docs/legosti/fy96/7332b.pdf].

RESNET. 2006. Procedures for Verification of RESNET Accredited HERS Software Tools. RESNET Publication No. 06-002. Residential Energy Services Network, Inc. Oceanside, CA. December.

[http://www.resnet.us/programs/software/verification.pdf].

Ternes, Mark P. 2007. Validation of the Manufactured Home Energy Audit (MHEA). ORNL/CON-501. Oak Ridge National Laboratory, Oak Ridge, TN. November.

[http://apps.ornl.gov/ pts/prod/pubs/ldoc8463_con_501.pdf]. 


\section{APPENDIX A. CHANGES MADE IN MHEA DURING THE BESTEST ANALYSES}

The changes listed in this appendix were made to MHEA as part of the BESTEST UA analysis described in Sect. 2.1 unless otherwise noted.

\section{A.1. MHEA SETUP LIBRARY, KEY PARAMETERS TAB}

\section{Set Points Tab:}

Thermostat setback amount - Value changed from $5^{\circ} \mathrm{F}$ to $3^{\circ} \mathrm{F}$.

\section{Insulation Tab:}

$\underline{\text { Wall }}$

Summer exterior film resistance - R-value changed from 0.25 to 0.465 .

Winter exterior film resistance - R-value changed from 0.17 to 0.425 .

Summer interior wall - R-value changed from 1.03 to 0.45 . This is now the R-value for the interior surface material of exterior walls for the mobile home itself and any room additions. Previously, this was the R-value for the interior surface material for just room additions; the R-value for the mobile home interior surface material previously used in the code was 0.35 ).

Winter interior wall - R-value changed from 1.03 to 0.45 . This is now the R-value for the interior surface material of exterior walls for the mobile home itself and any room additions. Previously, this was the R-value for the interior surface material for just room additions; the R-value for the mobile home interior surface material previously used in the code was $0.35)$.

Floor

Summer interior floor - R-value changed from 2.61 to 3.2 .

Winter interior floor - R-value changed from 2.92 to 3.2 .

\section{Ceiling}

Summer interior ceiling - R-value changed from 1.32 to 1.22 .

Winter interior ceiling - R-value changed from 1.01 to 1.22 .

\section{Heat Transfer Tab:}

Daytime internal loads - Value changed from 2400 to $1950 \mathrm{Btu} / \mathrm{h}$ (changed after the BESTEST and RESNET analyses as described in Sect. 4.3).

Night time internal loads - Value changed from 1000 to $2350 \mathrm{Btu} / \mathrm{h}$ (changed after the BESTEST and RESNET analyses as described in Sect. 4.3).

\section{Door Tab:}

Solid core - U-value changed from 0.33 to 0.4 .

Standard manufactured home door - U-value changed from 0.14 to 0.4.

Replacement door - U-value changed from 0.14 to 0.2 (not implemented until all the analyses described in this report were completed). 


\section{Windows Tab:}

Single-pane, summer - U-value changed from 1.04 to 0.93 .

Single-pane, winter - U-value changed from 1.1 to 0.93 .

Single-pane, plastic storm, summer - U-value changed from 0.55 to 0.53 .

Single-pane, plastic storm, winter - U-value changed from 0.55 to 0.53 .

Single-pane, glass storm, summer - U-value changed from 0.5 to 0.48 .

Single-pane, glass storm, winter - U-value changed from 0.5 to 0.48 .

Double-pane, summer - U-value changed from 0.61 to 0.57 .

Double-pane, winter - U-value changed from 0.58 to 0.57 .

Double-pane, plastic storm, summer - U-value changed from 0.4 to 0.43 .

Double-pane, plastic storm, winter - U-value changed from 0.4 to 0.43 .

Double-pane, glass storm, summer - U-value changed from 0.35 to 0.38 .

Double-pane, glass storm, winter - U-value changed from 0.35 to 0.38 .

\section{A.2. CHANGES IN THE MHEA ALGORITHMS}

Wall:

Changed the framing factor from $15 \%$ to $20 \%$.

R-value of 1 added to the total R-value for the wall assembly (changed after the BESTEST and RESNET analyses as described in Sect. 4.3).

Floor:

Modified the cavity R-value calculations.

Included consideration of an air cavity in the wing section.

Modified the heat transfer calculations through the perimeter.

Modified the heat transfer calculations associated with the presence of an outside water closet.

Changed the exterior film coefficients: value with skirting present from 0.92 to 0.765 , and value without skirting from 0.92 to 0.488 .

R-value of 1 added to the total R-value for the floor assembly (changed after the BESTEST and RESNET analyses as described in Sect. 4.3).

\section{Ceiling:}

Modified the parallel heat flow path calculations.

Included insulation in the framing path if the depth is greater than the joist height.

Changed the exterior film coefficient from 1.05 to 1.4.

$\mathrm{R}$-value of 1 added to the total R-value for the ceiling assembly (changed after the BESTEST and RESNET analyses as described in Sect. 4.3).

\section{Infiltration:}

Infiltration load reduced by $25 \%$ (changed after the BESTEST and RESNET analyses as described in Sect. 4.3).

\section{Heating System:}

HSPFs for heat pumps modified to take into account dependence on climate (changed as part of the RESNET analyses as described in Sect. 3). 


\section{INTERNAL DISTRIBUTION}

1-10. M. T. Eady

11. J. F. Eisenberg

12. M. B. Gettings
13-23. M. P. Ternes

24. ORNL Office of Technical Information and Classification

\section{EXTERNAL DISTRIBUTION}

25. Mr. Thomas Andrews, Ohio Energy Office, $26^{\text {th }}$ Floor, 77 South High Street, Columbus, OH 43215-6130

26. Mr. Dennis Biddle, Ohio Energy Office, $26^{\text {th }}$ Floor, 77 South High Street, Columbus, OH 43215

27. Mr. James Childs, U.S. Department of Energy, EE-2K/Forrestal Building, 1000 Independence Avenue, S.W., Washington, DC 20585

28. Mr. Robert DeSoto, U.S. Department of Energy, Golden Field Office, MS 1501, 1617 Cole Boulevard, Golden, CO 80401

29. Ms. Jean Diggs, U.S. Department of Energy, EE-2K/Forrestal Building, 1000 Independence Avenue, S.W., Washington, DC 20585

30. Mr. Ted Koenig, Missouri Department of Natural Resources, Energy Center, 1659 East Elm, Jefferson City, MO 65102-0176

31. Mr. Tim Lenahan, Ohio Energy Office, $26^{\text {th }}$ Floor, 77 South High Street, Columbus, OH 43215

32. Mr. Dave Like, Department of Social Services, Office of Energy Assistance, 206 W Missouri Avenue, Pierre, SD 57501

33. Mr. Alex Moore, D\&R International, Ltd., Suite 500, 1300 Spring Street, Silver Spring, MD 20910

34. Mr. Michael Peterson, U.S. Department of Energy, Golden Field Office, MS 1502, 1617 Cole Boulevard, Golden, CO 80401

35. Mr. Charlie Richardson, Longs Peak Energy Conservation, Suite J, 2450 Central Avenue, Boulder, CO 80301

36. Mr. Gregg Riley, King County Housing Authority, $1545565^{\text {th }}$ Avenue South, Seattle, WA 98188

37. Mr. Bob Scott, West Virginia Governor's Office of Economic Opportunity, $3^{\text {rd }}$ Floor, 950 Kanawha Boulevard East, Charleston, WV 25301

38. Mr. Cal Steiner, North Dakota Department of Commerce, 1600 East Century Avenue, Bismarck, ND 58503

39. Mr. Geoff Wilcox, Vermont Office of Economic Opportunity, 103 South Main Street, Waterbury, VT 05671 